Supporting Information

\title{
Photoinduced Charge Separation in Porphyrin Ion Pairs
}

\author{
Mirco Natali, * Franco Scandola
}

Dipartimento di Scienze Chimiche e Farmaceutiche, Università degli Studi di Ferrara, via Fossato di Mortara 17-19, and Centro Interuniversitario per la Conversione Chimica dell'Energia Solare, sezione di Ferrara, via L. Borsari 46, 44121 Ferrara, Italy. 


\section{Photophysics of porphyrins $\mathrm{Zn} 1, \mathrm{Zn} 2, \mathrm{H}_{2} 1$, and $\mathrm{H}_{2} 2$}

The following data refer to the photophysics of the porphyrin monomers in 50/50 methanol/water, but the results can be safely taken as a reference for the remaining solvents.

Zn1 monomer. Excitation of the tetracationic zinc porphyrin Zn1 yields the singlet excited state which can be detected by ultrafast spectroscopy (Figure A).

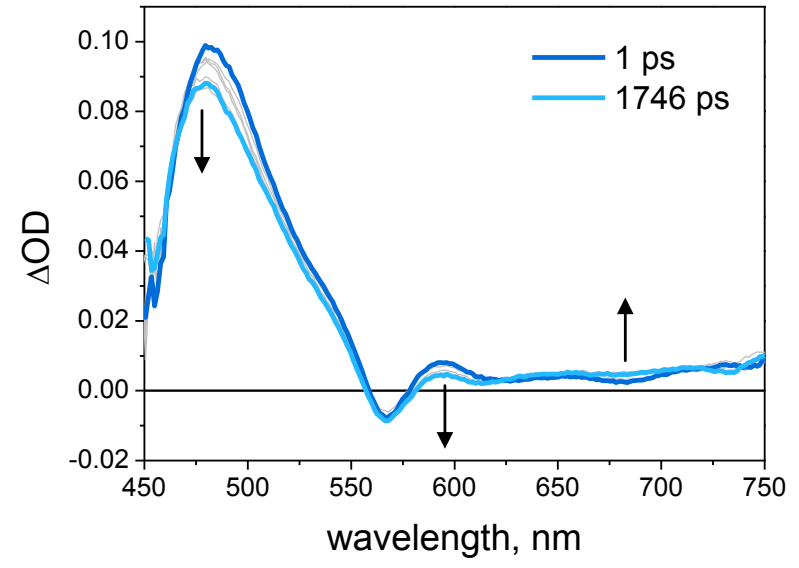

Figure A. Ultrafast spectroscopy (excitation at $400 \mathrm{~nm}$ ) of the Zn1 monomer.

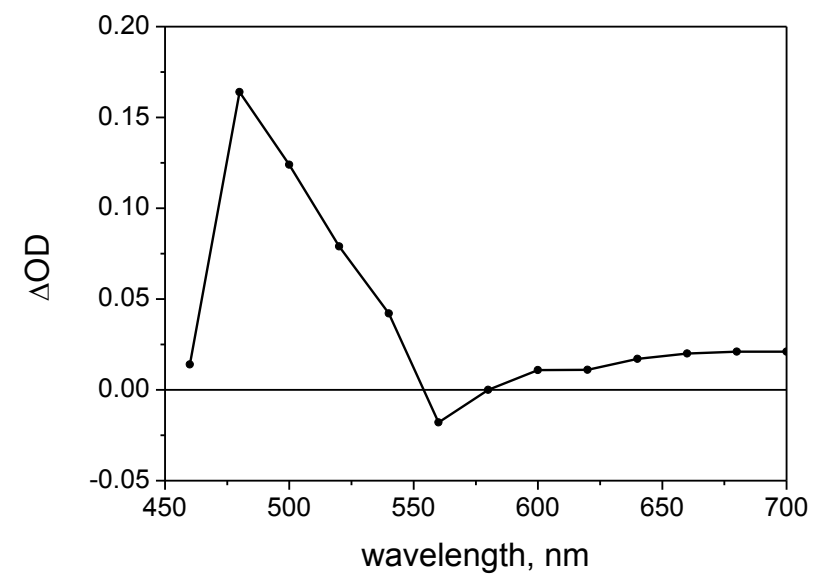

Figure B. Transient spectrum of the triplet excited state of $\mathrm{Zn} 1$ obtained by laser flash photolysis. 
Its transient spectrum displays a strong absorption centered at $480 \mathrm{~nm}$ with a tail at longer wavelengths and superimposed Q-band bleaches (564 and $620 \mathrm{~nm}$ ) and stimulated emission (apparent bleaching at 620 and $680 \mathrm{~nm}$ ). During its lifetime (ca $1.4 \mathrm{~ns}$, as determined from timeresolved emission experiments, Figure S5a) it undergoes intersystem crossing to the triplet excited state $(\Phi=0.9$ in pure water, Kalyanasundaram, K.; Neumann-Spallart, M. J. Phys. Chem. 1982, 86, 5163-5169) as monitored from the slight decrease of the 480-nm absorption and the disappearance of the stimulated emission features. The triplet excited state as monitored by laser flash photolysis (Figure B) has a lifetime of ca $1.6 \mu$ s under aerated conditions.

Zn2 monomer. As monitored by ultrafast spectroscopy, the Zn2 species, upon excitation, undergoes a rapid ( $\tau=1 \mathrm{ps)} \mathrm{relaxation} \mathrm{to} \mathrm{the} \mathrm{singlet} \mathrm{excited} \mathrm{state} \mathrm{(Figure} \mathrm{C}$, top panel), whose transient spectrum features a strong absorption centered at $455 \mathrm{~nm}$ with a tail at longer wavelengths and superimposed Q-band bleaches (558 and $605 \mathrm{~nm}$ ) and stimulated emission (apparent bleaching at 605 and $660 \mathrm{~nm}$ ). Its lifetime is of ca $2 \mathrm{~ns}$ (as determined from time-resolved emission experiments, Figure S5b), during which it undergoes intersystem crossing to the triplet excited state ( $\Phi=0.84$ in pure water, Kalyanasundaram, K.; Neumann-Spallart, M. J. Phys. Chem. 1982, 86, 5163-5169). This process can be followed only partially by ultrafast spectroscopy (Figure C, bottom panel) and is accompanied by the enhancement of the 455-nm absorption and the Q-band bleaches together with the loss of the stimulated emission. The triplet excited state as monitored by laser flash photolysis (Figure D) has a lifetime of ca $1.2 \mu$ s under aerated conditions. 

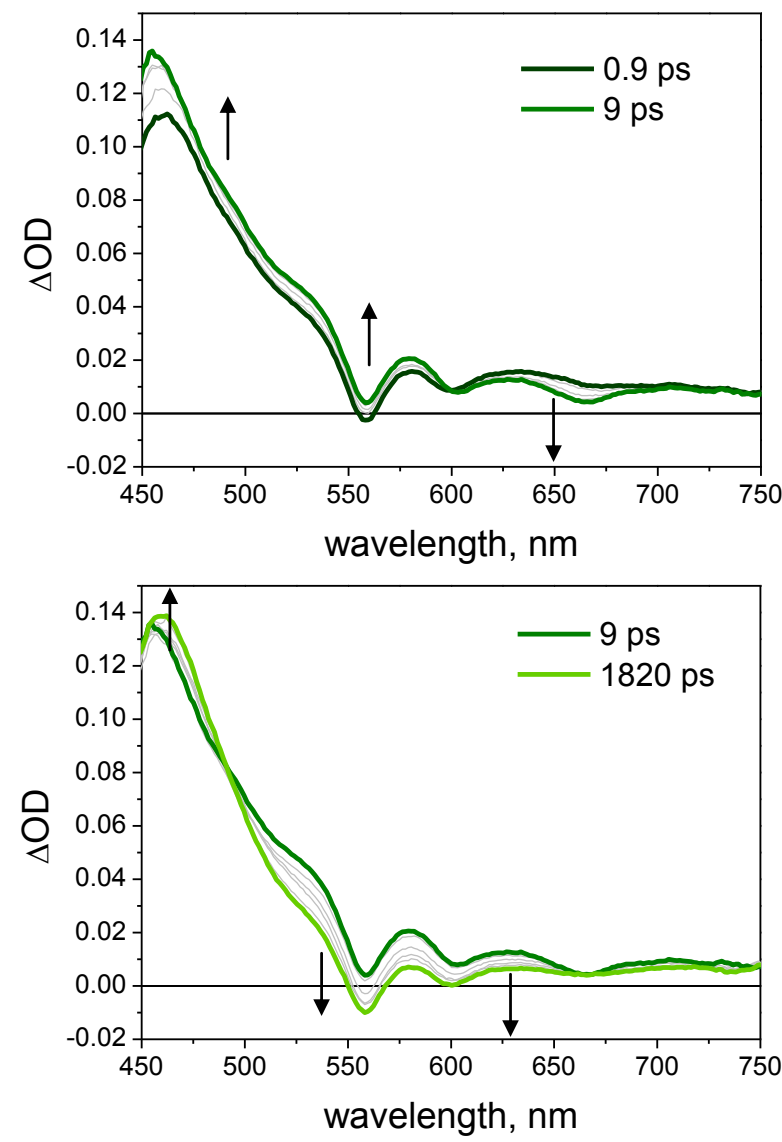

Figure C. Ultrafast spectroscopy (excitation at $400 \mathrm{~nm}$ ) of the $\mathrm{Zn} 2$ monomer.

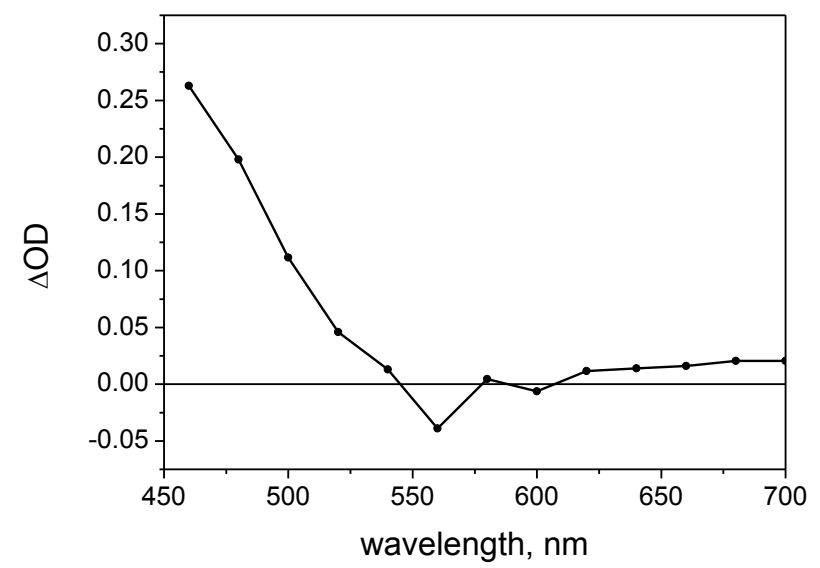

Figure D. Transient spectrum of the triplet excited state of $\mathrm{Zn} 2$ obtained by laser flash photolysis.

$\mathbf{H}_{2} 1$ monomer. Excitation of the $\mathrm{H}_{2} 1$ porphyrin yields the singlet excited state, whose transient spectrum (Figure E) features a strong absorption centered at $455 \mathrm{~nm}$ with a tail at longer 
wavelengths and superimposed Q-band bleaches (522, 590, and $630 \mathrm{~nm}$ ) and stimulated emission (650 and $720 \mathrm{~nm}$ ) and maintains almost a constant profile during the time window of the ultrafast spectroscopy apparatus (2000 ps). It has a lifetime of ca 9 ns, as determined from time-resolved emission experiments (Figure S11a).

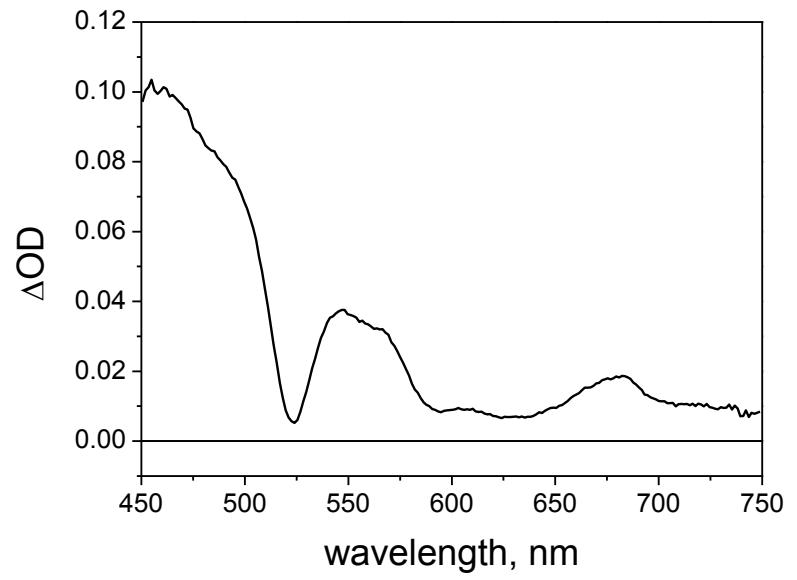

Figure E. Ultrafast spectroscopy (excitation at $400 \mathrm{~nm}$ ) of the $\mathrm{H}_{2} \mathbf{1}$ monomer (the spectrum is appreciably constant between 0-2000 ps).

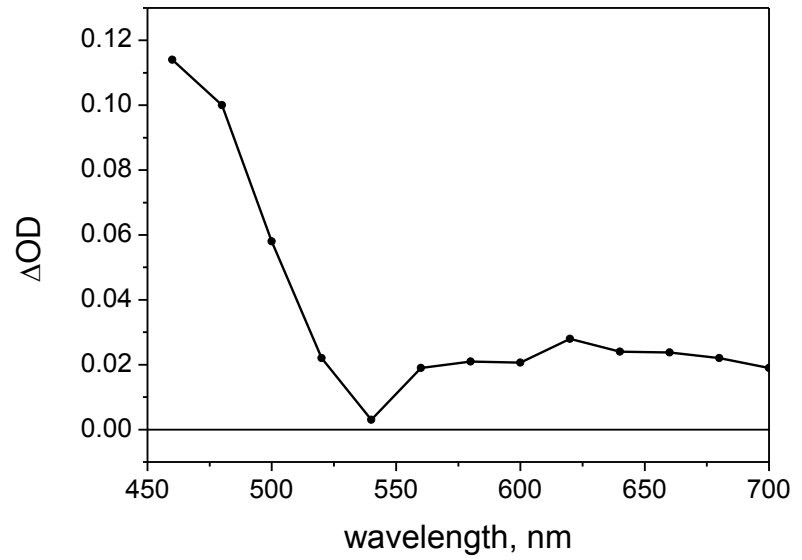

Figure F. Transient spectrum of the triplet excited state of $\mathrm{H}_{2} \mathbf{1}$ obtained by laser flash photolysis.

The triplet excited state, which is formed upon intersystem crossing from the singlet $(\Phi=0.92$ in pure water, Kalyanasundaram, K.; Neumann-Spallart, M. J. Phys. Chem. 1982, 86, 5163-5169), 
shows somewhat similar spectral features (Figure F), differing essentially for the absence of the stimulated emission in the $650-750 \mathrm{~nm}$ range, and has a lifetime of ca $1 \mu$ s under aerated conditions.

$\mathbf{H}_{2} 2$ monomer. Excitation of the tetrasulphonated free-base porphyrin yields the singlet excited state. Its transient spectrum, as monitored by ultrafast spectroscopy (Figure G), displays a strong absorption in the blue region of the spectrum with a tail at longer wavelengths and superimposed Qband bleaches $(515,551,596$, and $650 \mathrm{~nm}$ ) and stimulated emission (apparent bleaches at 650 and $730 \mathrm{~nm})$ and is maintained almost constant during the ultrafast spectroscopy measurement in agreement with the lifetime of ca $12 \mathrm{~ns}$, as obtained from time-resolved emission experiments (Figure S18b).

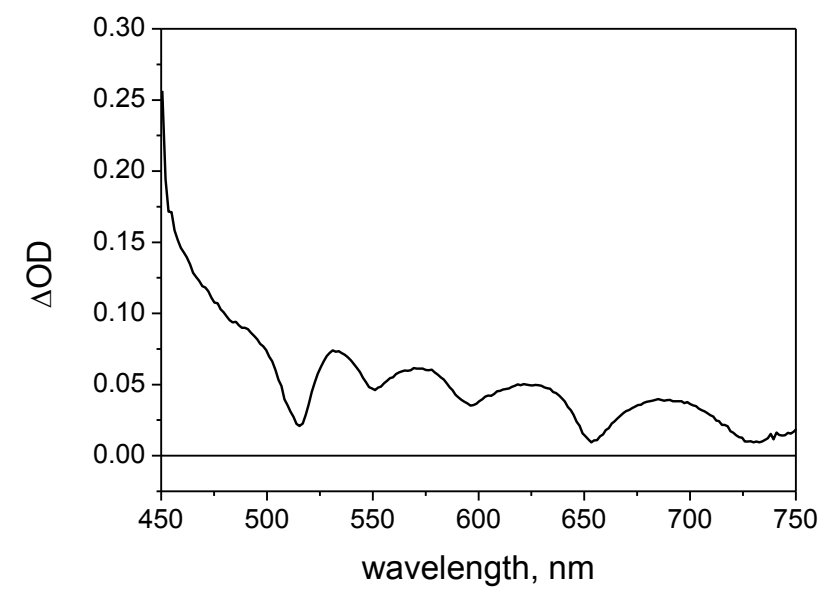

Figure G. Ultrafast spectroscopy (excitation at $400 \mathrm{~nm}$ ) of the $\mathrm{H}_{2} 2$ monomer (the spectrum is appreciably constant between 0-2000 ps).

The triplet excited state, formed upon intersystem crossing from the singlet $(\Phi=0.82$ in pure water, Kalyanasundaram, K.; Neumann-Spallart, M. J. Phys. Chem. 1982, 86, 5163-5169), shows similar spectral patterns (Figure H) but with the absence of stimulated emission bleaches and has a lifetime of ca $0.8 \mu$ s under aerated conditions. 


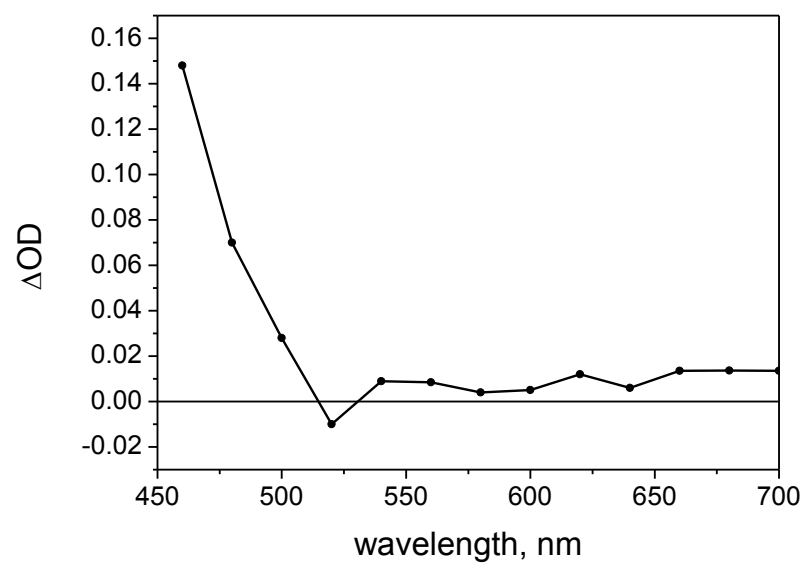

Figure H. Transient spectrum of the triplet excited state of $\mathrm{H}_{2} 2$ obtained by laser flash photolysis. 


\section{One-electron oxidation and reduction of porphyrin monomers}

As a general, preliminary comment it is worth pointing out that the generation of radical cation or anion species through electrochemical or chemical methods is prevented by the high probability of disproportionation reactions (see, e.g., Harriman, A. et al. J. Chem. Soc., Faraday Trans. 1 1983, 79, 1335-1350; Inisan, C. et al. New J. Chem. 1998, 823-830). We thus decided to use either the oxidative or reductive bimolecular quenching of the porphyrin triplet states by sacrificial agents to generate the one-electron oxidized or reduced species of the porphyrins via laser flash photolysis. As pointed out in the electrochemical section of the main text the tetracationic porphyrins $\mathrm{Zn} 1$ and $\mathrm{H}_{2} \mathrm{1}$ are expected to undergo reduction upon photoexcitation within the dimer, whereas the tetrasulphonated ones $\mathrm{Zn} 2$ and $\mathrm{H}_{2} \mathbf{2}$ are expected to oxidize.

Zn1 radical anion. The radical anion of the zinc tetracationic porphyrin $\mathrm{Zn} 1$ can be produced via bimolecular reductive quenching of the triplet excited state by ascorbic acid. The resulting difference absorption spectrum is reported in Figure I and is comparable to the one obtained by Neta (J. Phys. Chem. 1981, 85, 3678-3684) via pulse radiolysis.

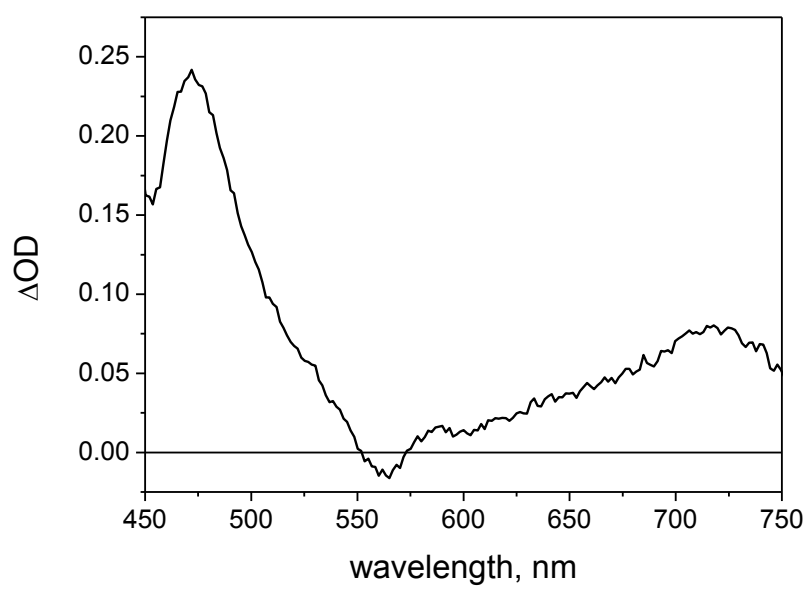

Figure I. Difference absorption spectrum of the Zn1 radical anion obtained by laser flash photolysis of an aqueous solution containing $30 \mu \mathrm{M} \mathrm{Zn} 1$ and $0.01 \mathrm{M}$ ascorbic acid (buffered at $\mathrm{pH} 4$ ). 
It features a strong absorption centered at $470 \mathrm{~nm}$ and a broader one in the red part of the spectrum (centered at $720 \mathrm{~nm}$ ) together with the Q-band bleaches at $564 \mathrm{~nm}$ and $600 \mathrm{~nm}$. This spectrum strongly differentiates from the one of the singlet excited state and the triplet excited state of $\mathrm{Zn} \mathbf{1}$ in particular for the larger intensities of the absorption patterns in the $650-750 \mathrm{~nm}$ region.

$\mathrm{Zn} 2$ radical cation. The radical anion of the zinc tetracationic porphyrin $\mathrm{Zn} 2$ can be produced via bimolecular oxidative quenching of the triplet excited state by $\mathrm{Co}\left(\mathrm{NH}_{3}\right)_{5} \mathrm{Cl}_{2}$. The resulting difference absorption spectrum is reported in Figure $\mathrm{J}$. The difference spectrum is characterized by a strong absorption in the blue region with a maximum at ca $450 \mathrm{~nm}$ and a broader absorption between $600-700 \mathrm{~nm}$. The Q-band bleaches $(552$ and $590 \mathrm{~nm}$ ) can be also discerned. This spectrum strongly differentiates from those of the singlet and triplet excited states of $\mathrm{Zn} 2$ in particular for the larger intensities in the red region of the spectrum.

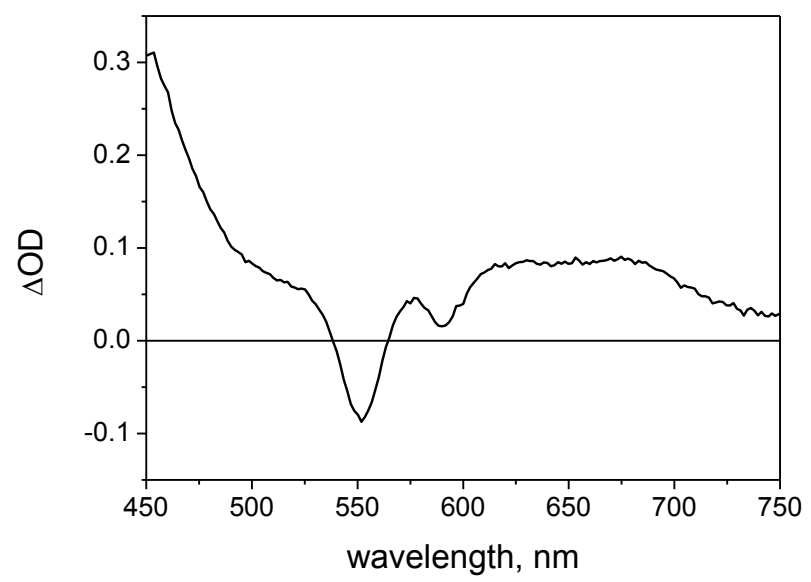

Figure J. Difference absorption spectrum of the Zn2 radical cation obtained by laser flash photolysis of an aqueous solution containing $50 \mu \mathrm{M} \mathrm{Zn} 2$ and $1 \mathrm{mM} \mathrm{Co}\left(\mathrm{NH}_{3}\right)_{5} \mathrm{Cl}_{2}$.

$\mathbf{H}_{2} 1$ radical anion. The radical anion of the zinc tetracationic porphyrin $\mathrm{Zn} 1$ can be produced via bimolecular reductive quenching of the triplet excited state by ascorbic acid. The resulting 
difference absorption spectrum is reported in Figure $\mathrm{K}$ and show the presence of a strong absorption in particular in the red blue region with maximum at $500 \mathrm{~nm}$ with an intense tail at longer wavelengths. The weak superposition of the Q-band bleaches is also observed (520 and $590 \mathrm{~nm}$ ). The appreciably large intensities of the difference spectrum between 600-750 nm are thus diagnostic for the $\mathrm{H}_{2} \mathbf{1}$ radical anion when compared to the transient absorption spectra of the singlet excited state and the triplet excited state.

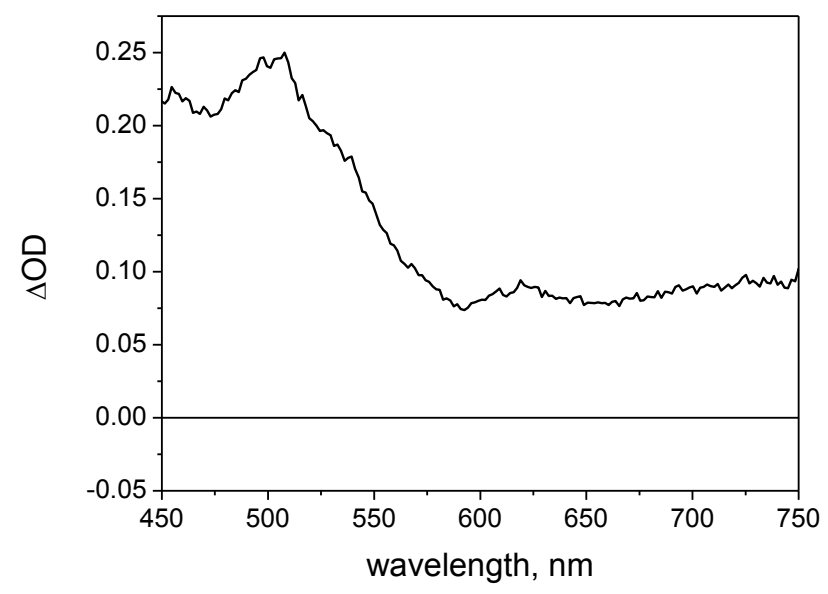

Figure K. Difference absorption spectrum of the $\mathrm{H}_{2} \mathbf{1}$ radical anion obtained by laser flash photolysis of an aqueous solution containing $30 \mu \mathrm{M} \mathrm{H}_{2} \mathbf{1}$ and $0.01 \mathrm{M}$ ascorbic acid (pH 4).

$\mathbf{H}_{2} 2$ radical cation. The differential absorption spectrum of the one-electron oxidized $\mathrm{H}_{2} 2$ species cannot be obtained through oxidative quenching by laser flash photolysis measurements using common quenchers such as $\mathrm{Co}\left(\mathrm{NH}_{3}\right)_{5} \mathrm{Cl}_{2}$ (owing to a disfavored thermodynamics) or persulfate (fast thermal degradation). The difference absorption spectrum of the radical cation of a tetraphenylporphyrin (Gasyna, Z. et al. J. Inorg. Chem. 1985, 24, 2440-2447) can be, however, taken as a reference for the spectrum of the $\mathrm{H}_{2} \mathbf{2}^{+}$species: It displays a strong absorption between 450-500 nm, Q-band bleaches, and a broad, intense absorption between 600 and $700 \mathrm{~nm}$ peaking at ca. $670 \mathrm{~nm}$. 
Figures of the Supporting Information
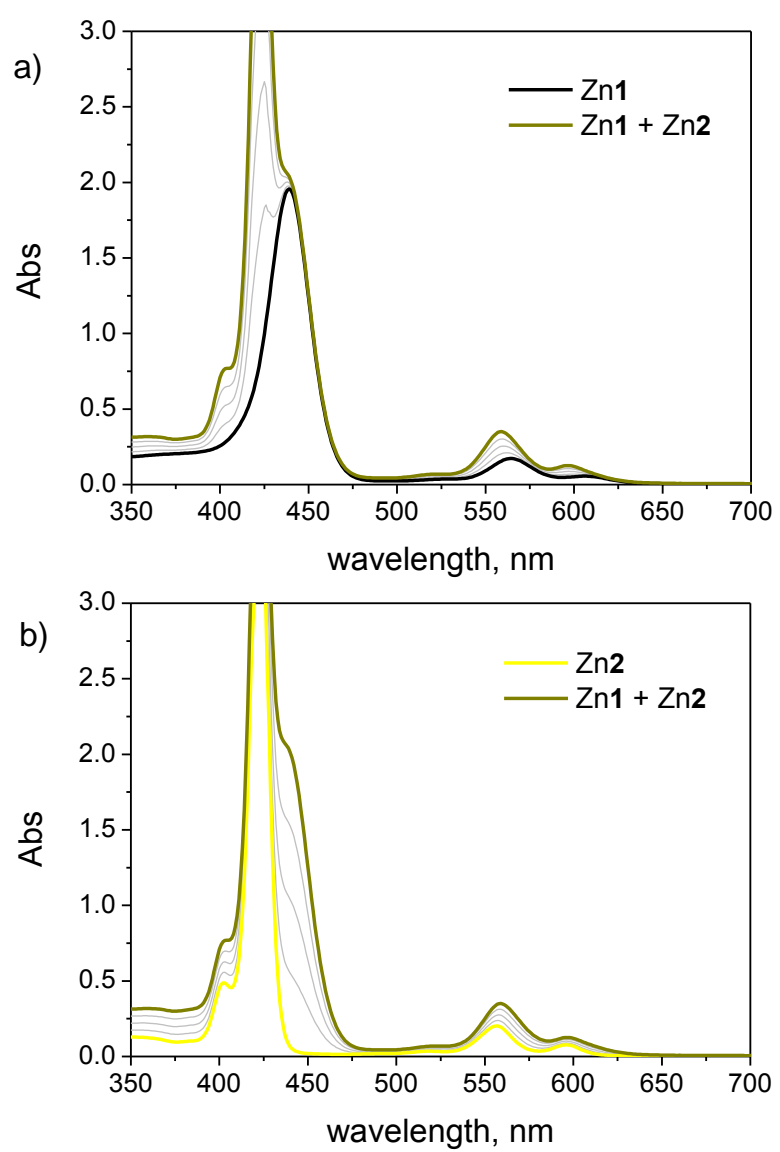

Figure S1. Simulation of the spectrophotometric titrations of (a) $10 \mu \mathrm{M} Z \mathrm{Zn} 1$ with $\mathrm{Zn} 2$ and (b) 10 $\mu \mathrm{M} Z \mathrm{Zn} 2$ with $\mathrm{Zn} 1$ in 50/50 methanol/water assuming non-interacting porphyrin species. 

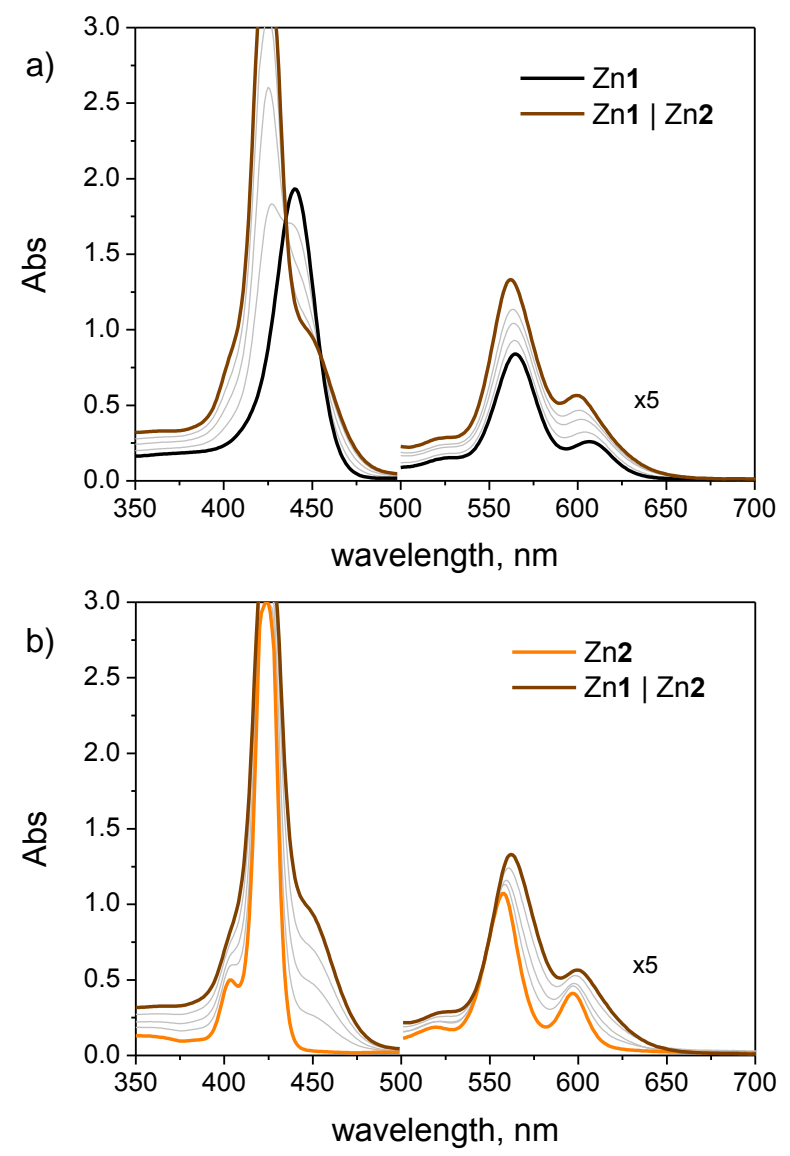

Figure S2. Spectrophotometric titration of (a) $10 \mu \mathrm{M} \mathrm{Zn} 1$ with $0-10 \mu \mathrm{M} \mathrm{Zn} 2$ (addition of $2.5 \mu \mathrm{M}$ amounts) and (b) $10 \mu \mathrm{M} \mathrm{Zn} 2$ with $0-10 \mu \mathrm{M} \mathrm{Zn} 1$ (addition of $2.5 \mu \mathrm{M}$ amounts) in $50 / 50$ ethanol/water. 

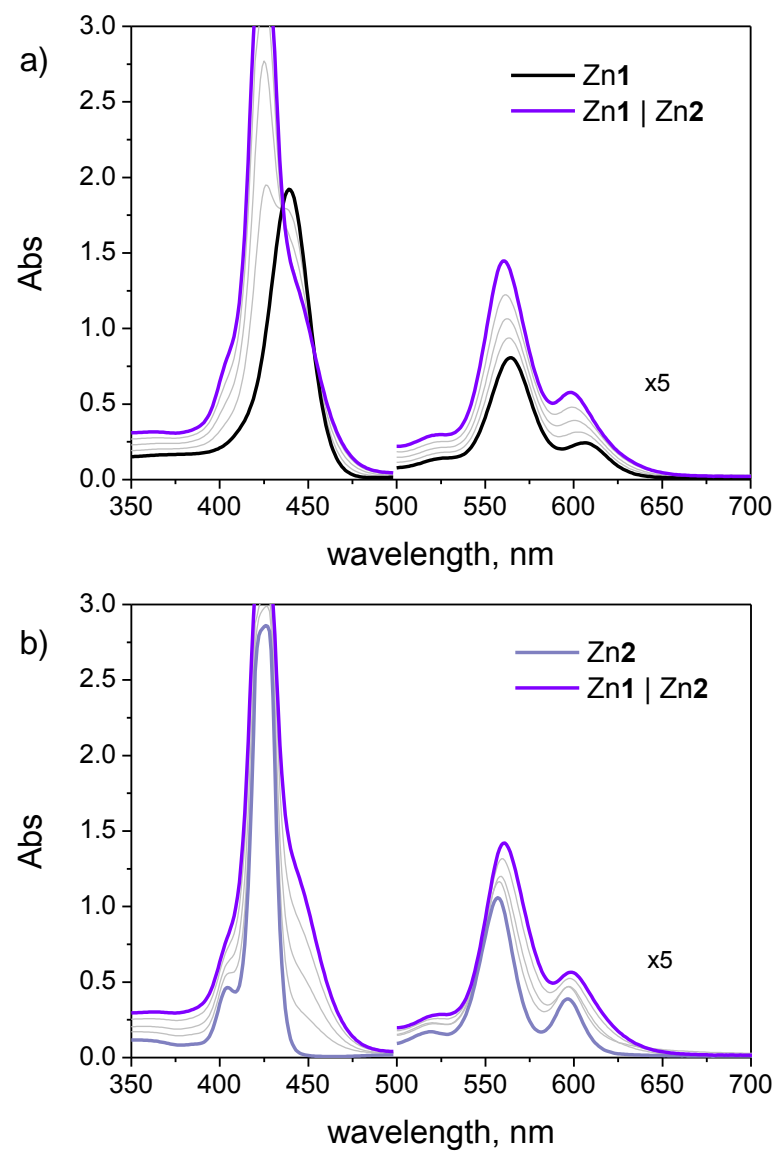

Figure S3. Spectrophotometric titration of (a) $10 \mu \mathrm{M} Z \mathrm{Zn} 1$ with $0-10 \mu \mathrm{M} \mathrm{Zn} 2$ (addition of $2.5 \mu \mathrm{M}$ amounts) and (b) $10 \mu \mathrm{M} Z \mathrm{Zn} 2$ with $0-10 \mu \mathrm{M} \mathrm{Zn} 1$ (addition of $2.5 \mu \mathrm{M}$ amounts) in 50/50 THF/water. 

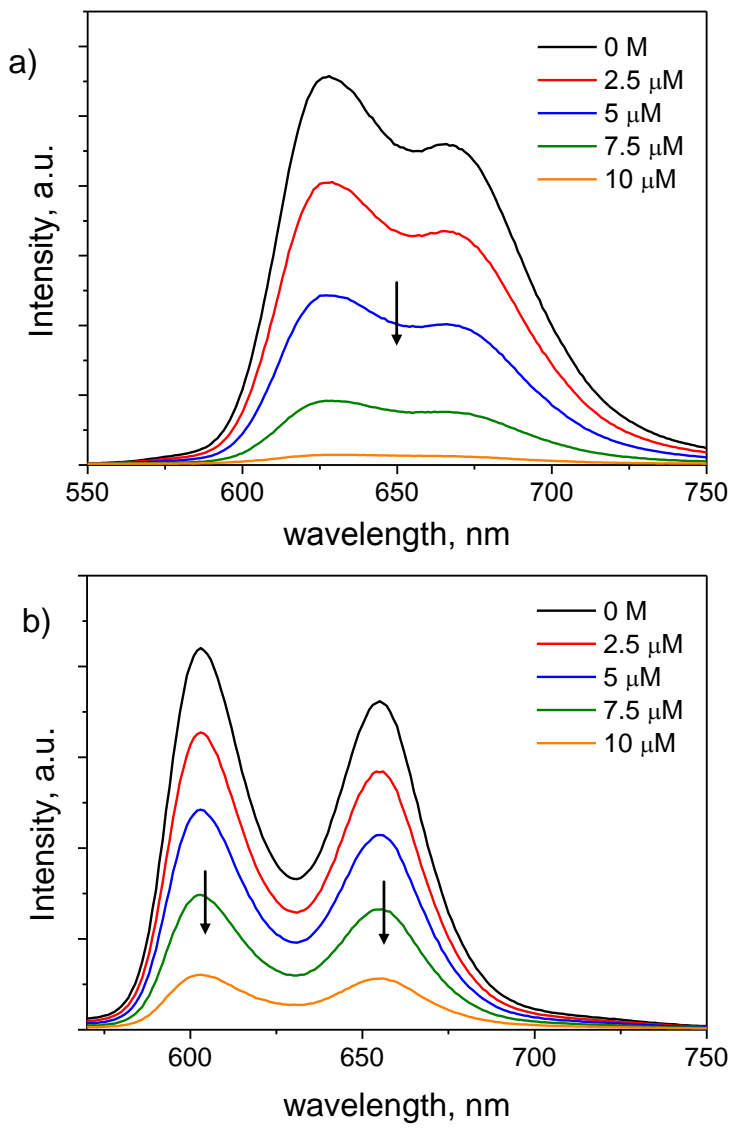

Figure S4. Photoluminescence spectra of 50/50 methanol/water mixtures containing (a) $10 \mu \mathrm{M} Z \mathrm{Zn} 1$ and $0-10 \mu \mathrm{M} Z \mathrm{Zn} 2$ (excitation at $456 \mathrm{~nm}$ ) or (b) $10 \mu \mathrm{M} \mathrm{Zn} 2$ and 0-10 $\mu \mathrm{M} \mathrm{Zn} 1$ (excitation at 544 $\mathrm{nm})$. 
a)

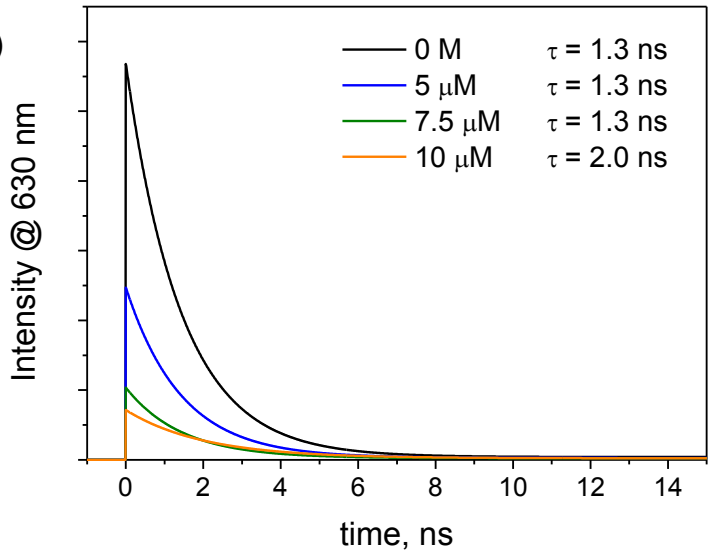

b)

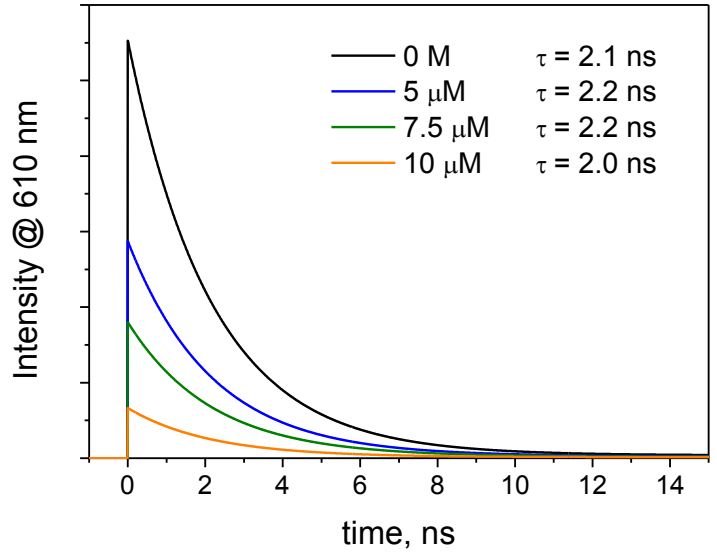

Figure S5. Time-resolved emission kinetics obtained by TC-SPC on 50/50 methanol/water mixtures containing (a) $10 \mu \mathrm{M} \mathrm{Zn1}$ and $0-10 \mu \mathrm{M} \mathrm{Zn2}$ (excitation at $600 \mathrm{~nm}$, analysis at $630 \mathrm{~nm}$ ) or (b) $10 \mu \mathrm{M} \mathrm{Zn2}$ and 0-10 $\mu \mathrm{M} \mathrm{Zn1} \mathrm{(excitation} \mathrm{at} 600 \mathrm{~nm}$, analysis at $610 \mathrm{~nm}$ ). 

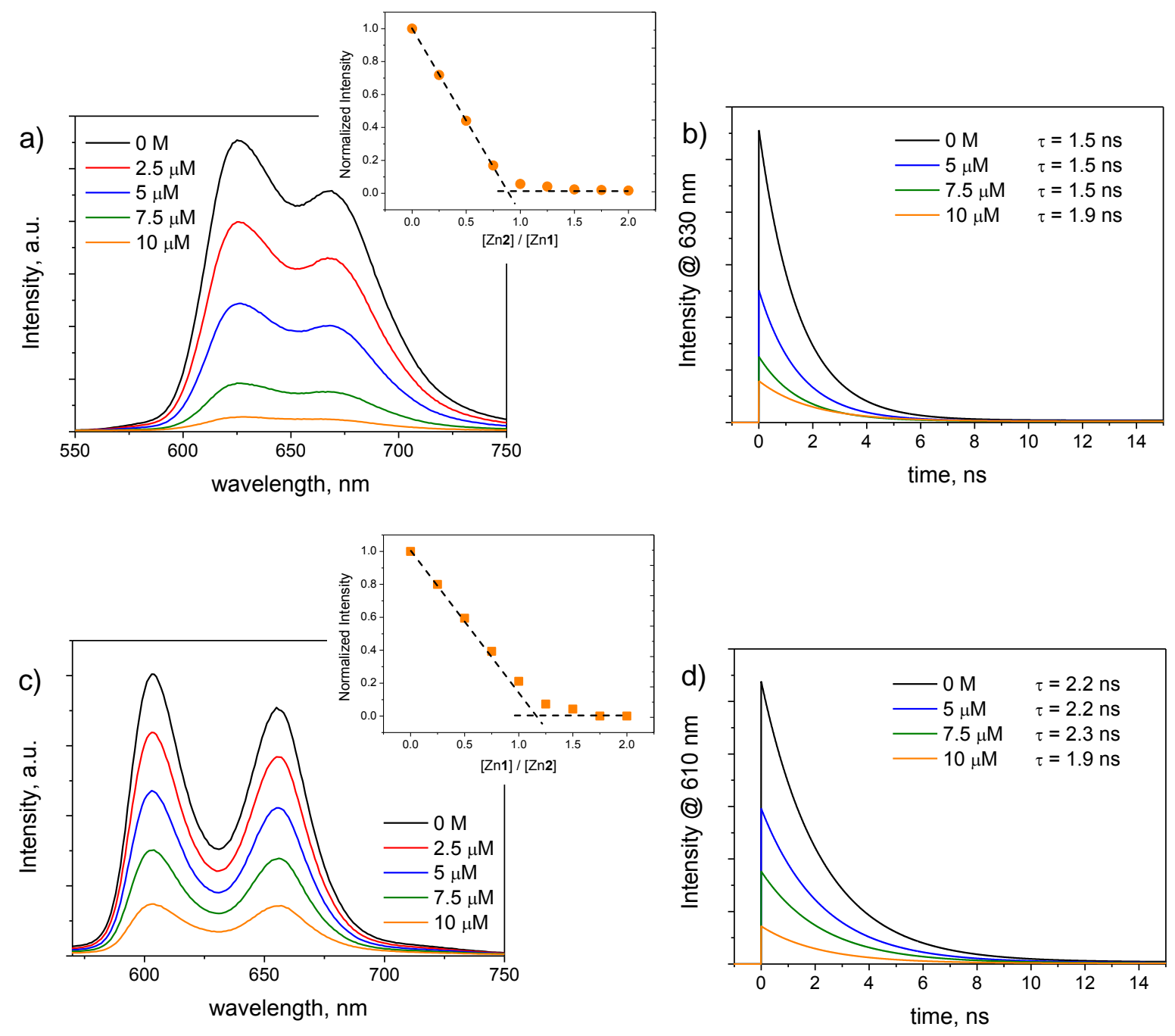

Figure S6. (a) Photoluminescence spectra (excitation at $456 \mathrm{~nm}$ ) and (b) time-resolved emission kinetics obtained by TC-SPC (excitation at $600 \mathrm{~nm}$, analysis at $630 \mathrm{~nm}$ ) of 50/50 ethanol/water mixtures containing $10 \mu \mathrm{M} \mathrm{Zn} 1$ and $0-10 \mu \mathrm{M} \mathrm{Zn} 2$. Inset: emission titration curve obtained by plotting the intensity of the $\mathrm{Zn1}$ fluorescence vs. [Zn2]/[Zn1]. (c) Photoluminescence spectra (excitation at $548 \mathrm{~nm}$ ) and (d) time-resolved emission kinetics obtained by TC-SPC (excitation at $600 \mathrm{~nm}$, analysis at $610 \mathrm{~nm}$ ) of 50/50 ethanol/water mixtures containing $10 \mu \mathrm{M} \mathrm{Zn2}$ and $0-10 \mu \mathrm{M}$ Zn1. Inset: emission titration curve obtained by plotting the intensity of the $\mathrm{Zn} 2$ fluorescence vs. $[\mathrm{Zn} 1] /[\mathrm{Zn} 2]$. In the emission titrations (insets) the fluorescence intensity is obtained from the emission spectra as the sole contribution of the spectrum of the titrated porphyrin according to spectral simulation. 

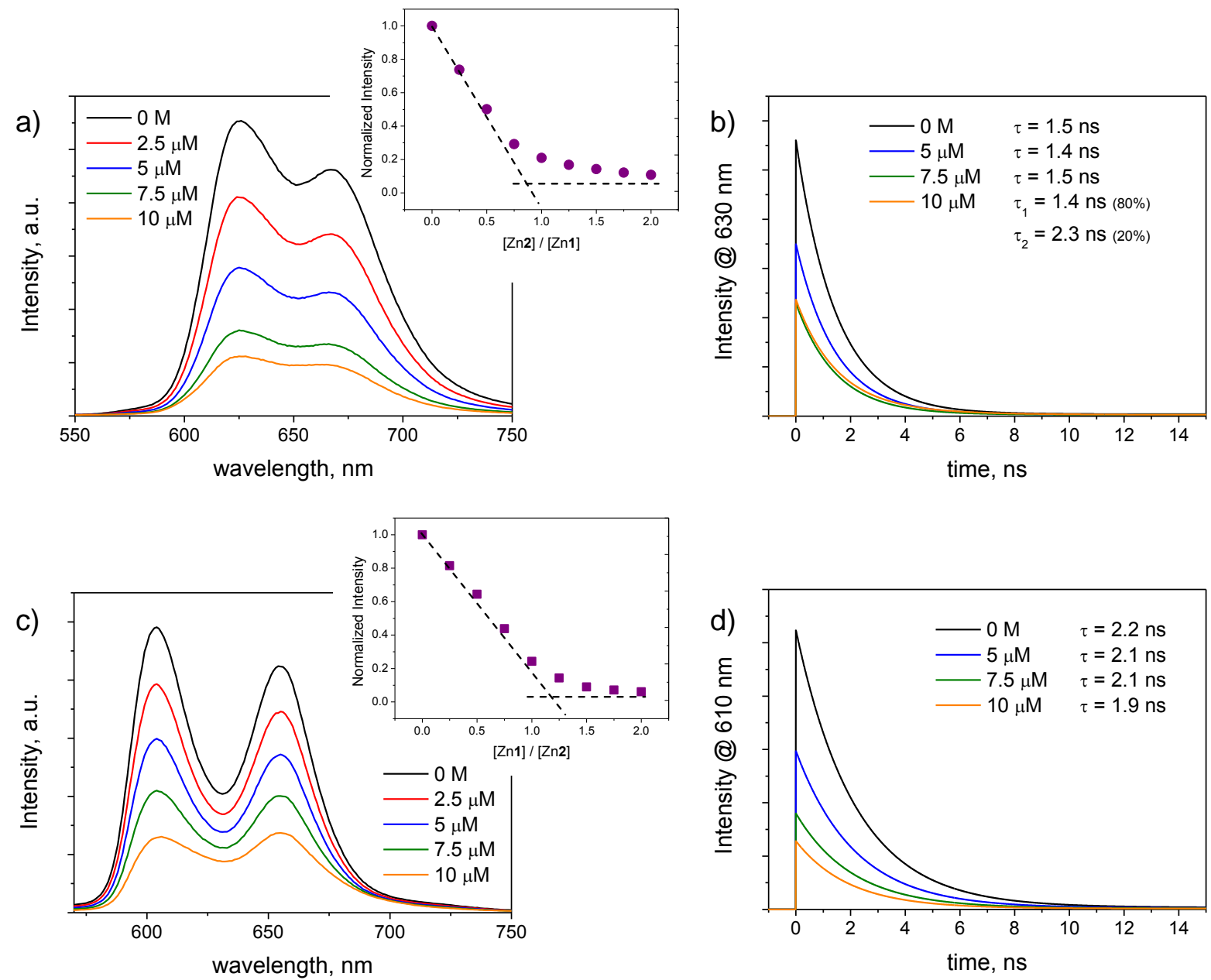

Figure S7. (a) Photoluminescence spectra (excitation at $454 \mathrm{~nm}$ ) and (b) time-resolved emission kinetics obtained by TC-SPC (excitation at $600 \mathrm{~nm}$, analysis at $630 \mathrm{~nm}$ ) of 50/50 THF/water mixtures containing $10 \mu \mathrm{M} \mathrm{Zn} 1$ and $0-10 \mu \mathrm{M} \mathrm{Zn} 2$. Inset: emission titration curve obtained by plotting the intensity of the $\mathrm{Zn} 1$ fluorescence vs. [Zn2]/[Zn1]. (c) Photoluminescence spectra (excitation at $547 \mathrm{~nm}$ ) and (d) time-resolved emission kinetics obtained by TC-SPC (excitation at $600 \mathrm{~nm}$, analysis at $610 \mathrm{~nm}$ ) of 50/50 THF/water mixtures containing $10 \mu \mathrm{M} \mathrm{Zn} 2$ and $0-10 \mu \mathrm{M}$ Zn1. Inset: emission titration curve obtained by plotting the intensity of the $\mathrm{Zn} 2$ fluorescence vs. $[\mathrm{Zn1}] /[\mathrm{Zn} 2]$. In the emission titrations (insets) the fluorescence intensity is obtained from the emission spectra as the sole contribution of the spectrum of the titrated porphyrin according to spectral simulation. 

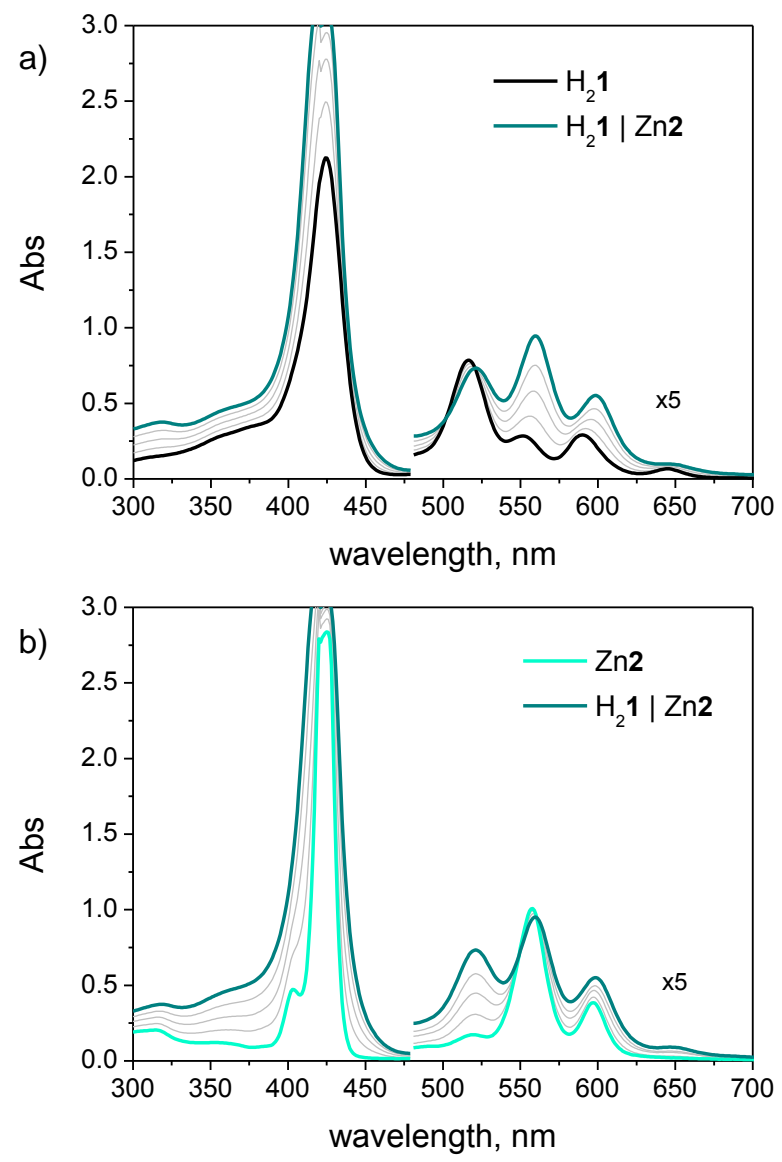

Figure S8. Spectrophotometric titration of (a) $10 \mu \mathrm{M} \mathrm{H}_{2} \mathbf{1}$ with $0-10 \mu \mathrm{M} \mathrm{Zn} 2$ (addition of $2.5 \mu \mathrm{M}$ amounts) and (b) $10 \mu \mathrm{M} \mathrm{Zn2}$ with $0-10 \mu \mathrm{M} \mathrm{H} \mathrm{H}_{2} 1$ (addition of $2.5 \mu \mathrm{M}$ amounts) in $50 / 50$ ethanol/water. 

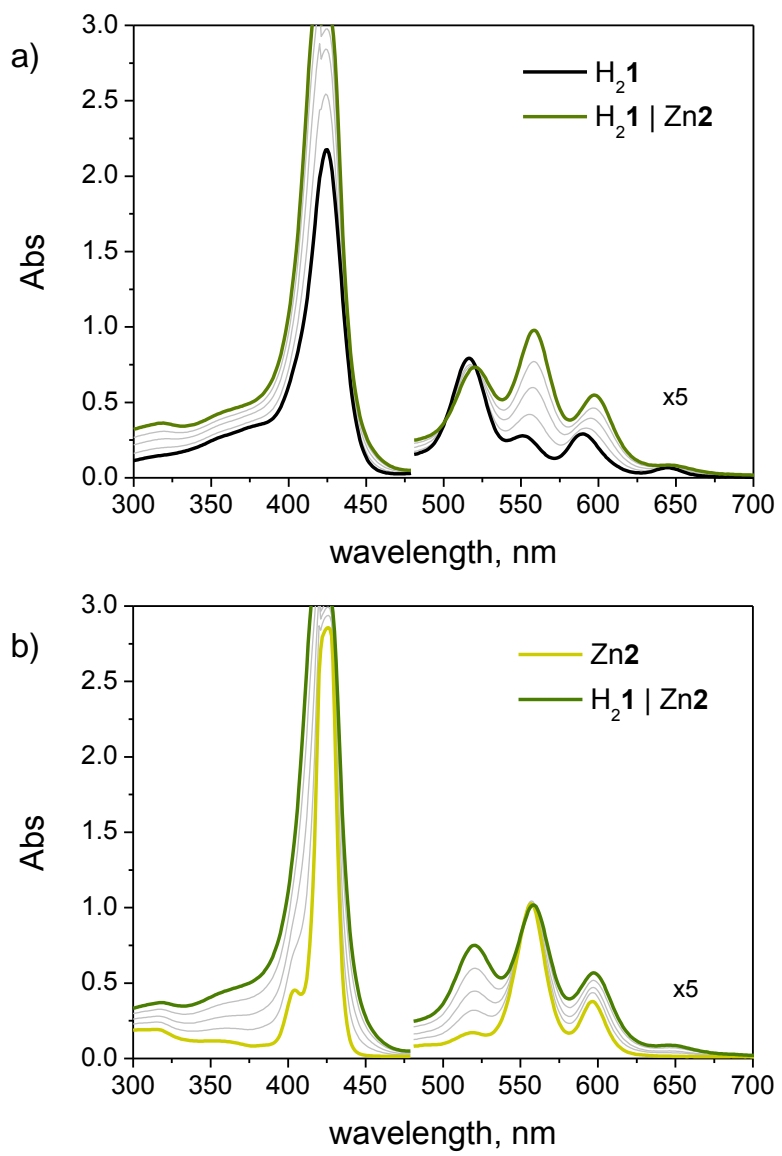

Figure S9. Spectrophotometric titration of (a) $10 \mu \mathrm{M} \mathrm{H} \mathrm{H}_{2} \mathbf{1}$ with $0-10 \mu \mathrm{M} \mathrm{Zn} 2$ (addition of $2.5 \mu \mathrm{M}$ amounts) and (b) $10 \mu \mathrm{M} \mathrm{Zn2}$ with 0-10 $\mu \mathrm{M} \mathrm{H}_{2} \mathbf{1}$ (addition of $2.5 \mu \mathrm{M}$ amounts) in 50/50 THF/water. 

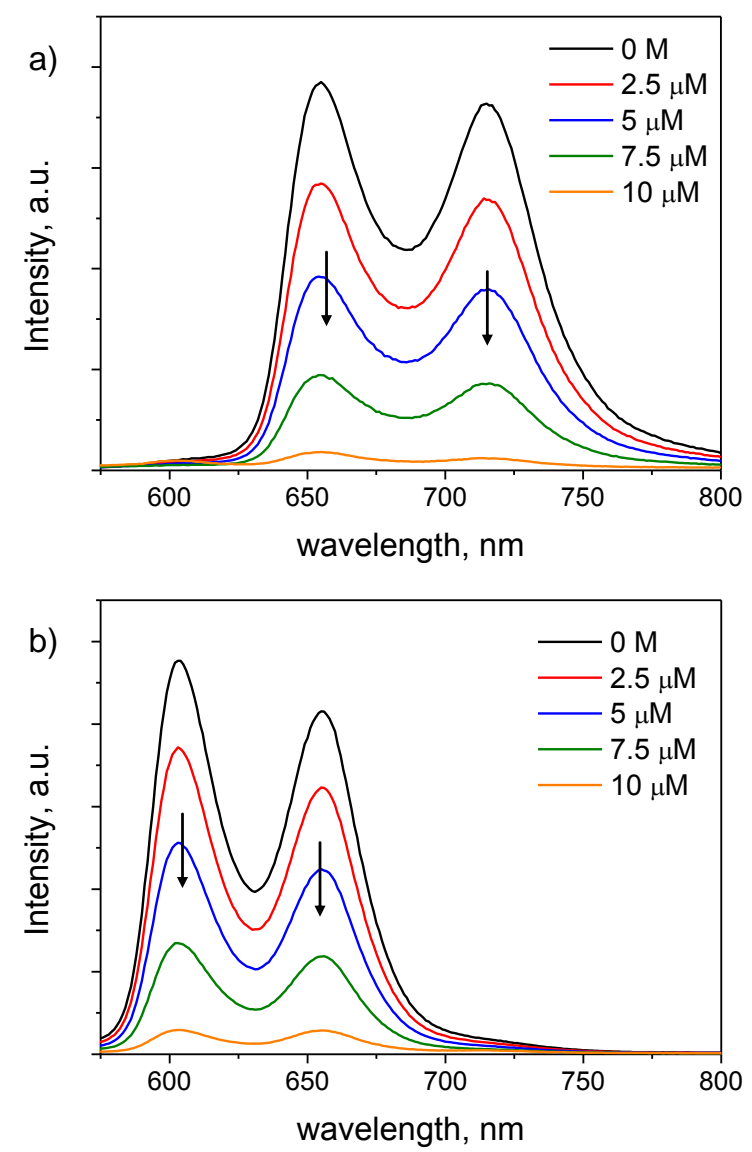

Figure S10. Photoluminescence spectra of 50/50 methanol/water mixtures containing (a) $10 \mu \mathrm{M}$ $\mathrm{H}_{2} 1$ and $0-10 \mu \mathrm{M} \mathrm{Zn} 2$ (excitation at $500 \mathrm{~nm}$ ) or (b) $10 \mu \mathrm{M} \mathrm{Zn} 2$ and 0-10 $\mu \mathrm{M} \mathrm{H}_{2} \mathbf{1}$ (excitation at 547 $\mathrm{nm})$. 

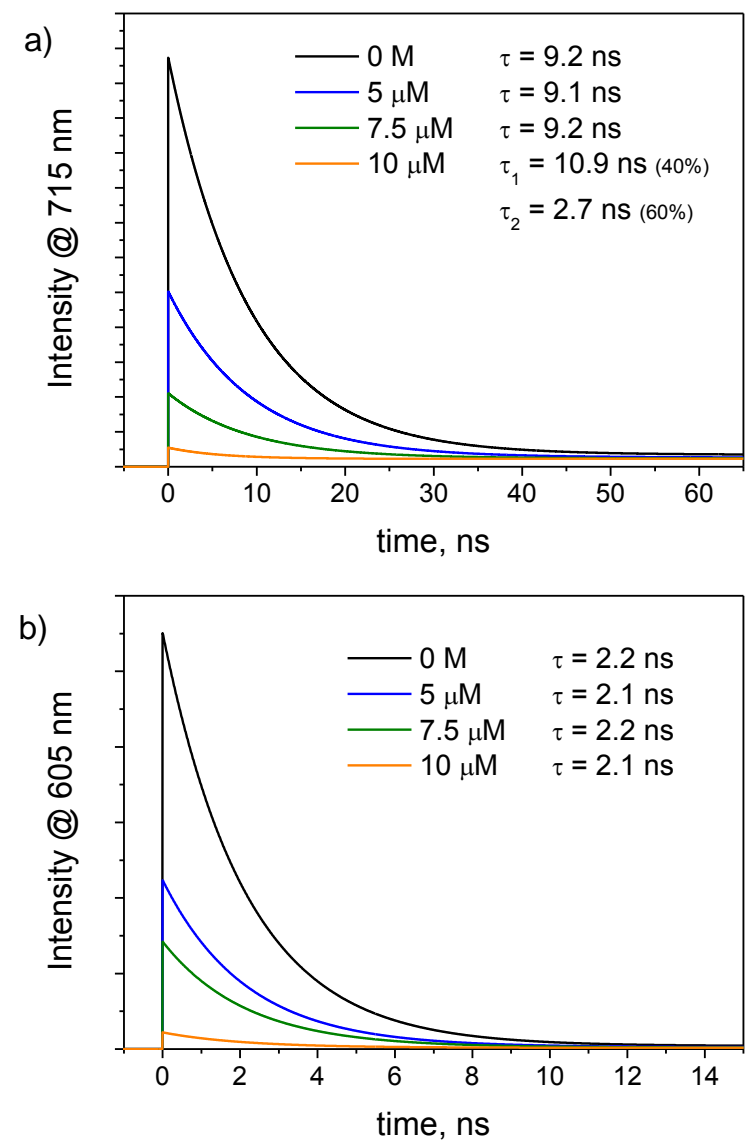

Figure S11. Time-resolved emission kinetics obtained by TC-SPC on 50/50 methanol/water mixtures containing (a) $10 \mu \mathrm{M} \mathrm{H}_{2} \mathbf{1}$ and $0-10 \mu \mathrm{M} \mathrm{Zn2} \mathrm{(excitation} \mathrm{at} 600 \mathrm{~nm}$, analysis at $715 \mathrm{~nm}$ ) or (b) $10 \mu \mathrm{M} \mathrm{Zn} 2$ and $0-10 \mu \mathrm{M} \mathrm{H}_{2} \mathbf{1}$ (excitation at $600 \mathrm{~nm}$, analysis at $605 \mathrm{~nm}$ ). 

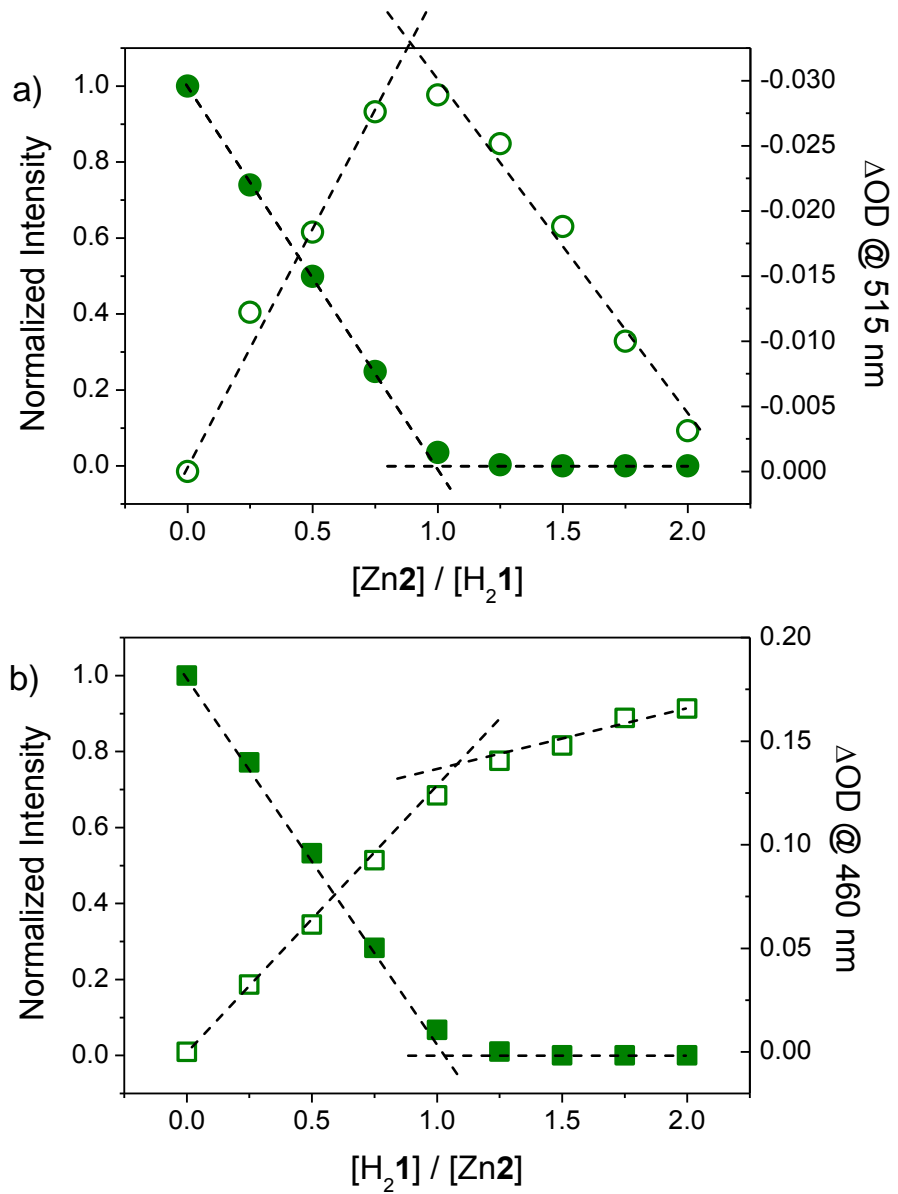

Figure S12. (a) Spectrophotometric (empty dots) and emission (full dots) titration of $10 \mu \mathrm{M} \mathrm{H}_{2} 1$ with Zn2 in 50/50 methanol/water and (b) spectrophotometric (empty squares) and emission (full squares) titration of $10 \mu \mathrm{M} \mathrm{Zn} 2$ with $\mathrm{H}_{2} 1$ in 50/50 methanol/water. In the emission titrations the fluorescence intensity is obtained from the emission spectra (Figure S10) as the sole contribution of the spectrum of the titrated porphyrin according to spectral simulation. 

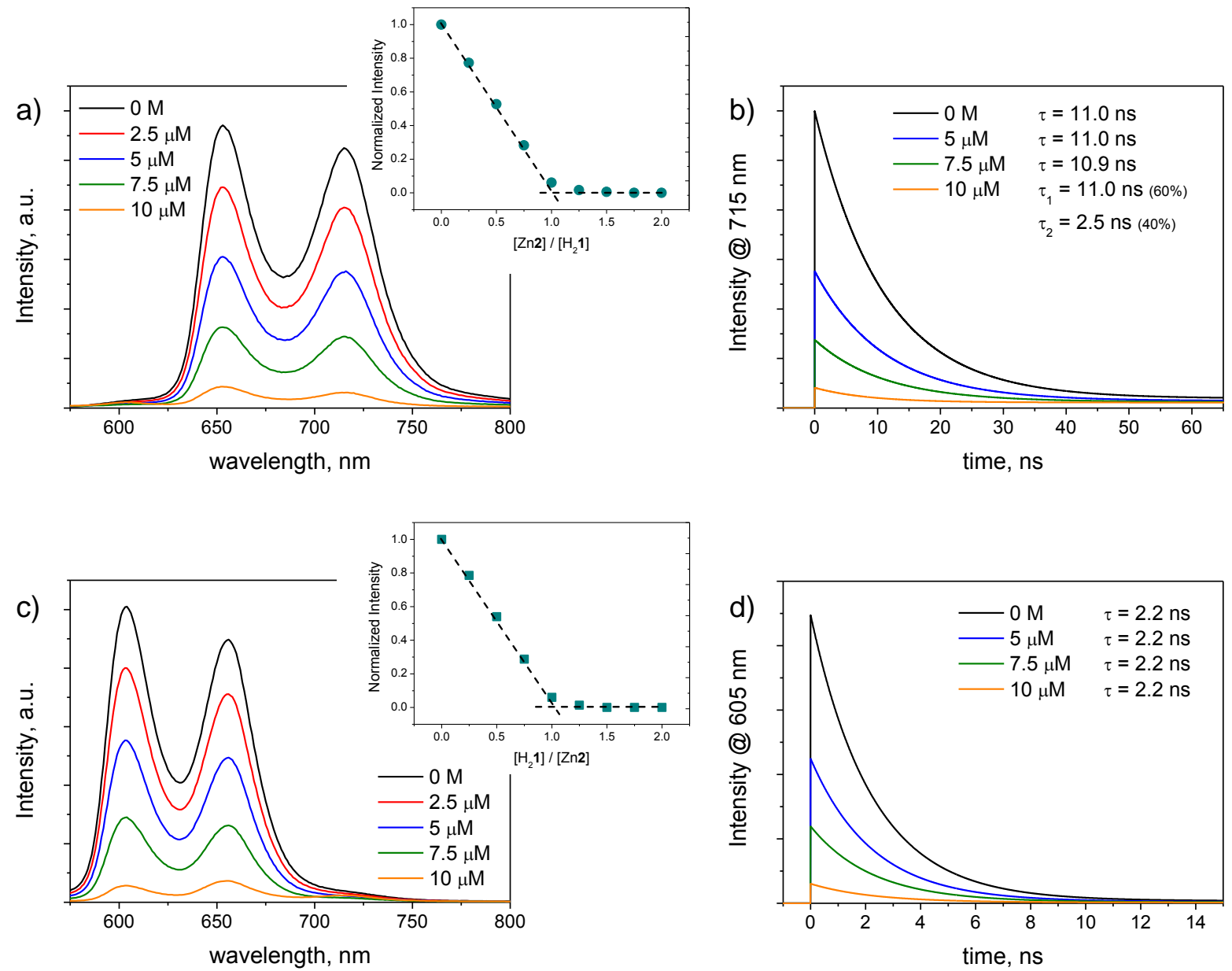

Figure S13. (a) Photoluminescence spectra (excitation at $502 \mathrm{~nm}$ ) and (b) time-resolved emission kinetics obtained by TC-SPC (excitation at $600 \mathrm{~nm}$, analysis at $715 \mathrm{~nm}$ ) of 50/50 ethanol/water mixtures containing $10 \mu \mathrm{M} \mathrm{H} \mathrm{H}_{2} \mathbf{1}$ and $0-10 \mu \mathrm{M} \mathrm{Zn} 2$. Inset: emission titration curve obtained by

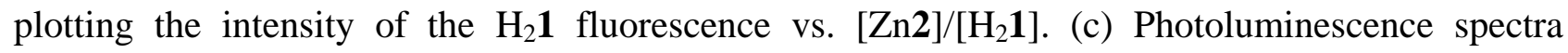
(excitation at $548 \mathrm{~nm}$ ) and (d) time-resolved emission kinetics obtained by TC-SPC (excitation at $600 \mathrm{~nm}$, analysis at $605 \mathrm{~nm}$ ) of 50/50 ethanol/water mixtures containing $10 \mu \mathrm{M} \mathrm{Zn2}$ and 0-10 $\mu \mathrm{M}$ $\mathrm{H}_{2}$ 1. Inset: emission titration curve obtained by plotting the intensity of the $\mathrm{Zn} 2$ fluorescence vs. $\left[\mathrm{H}_{2} 1\right] /[\mathrm{Zn} 2]$. In the emission titrations (insets) the fluorescence intensity is obtained from the emission spectra as the sole contribution of the spectrum of the titrated porphyrin according to spectral simulation. 

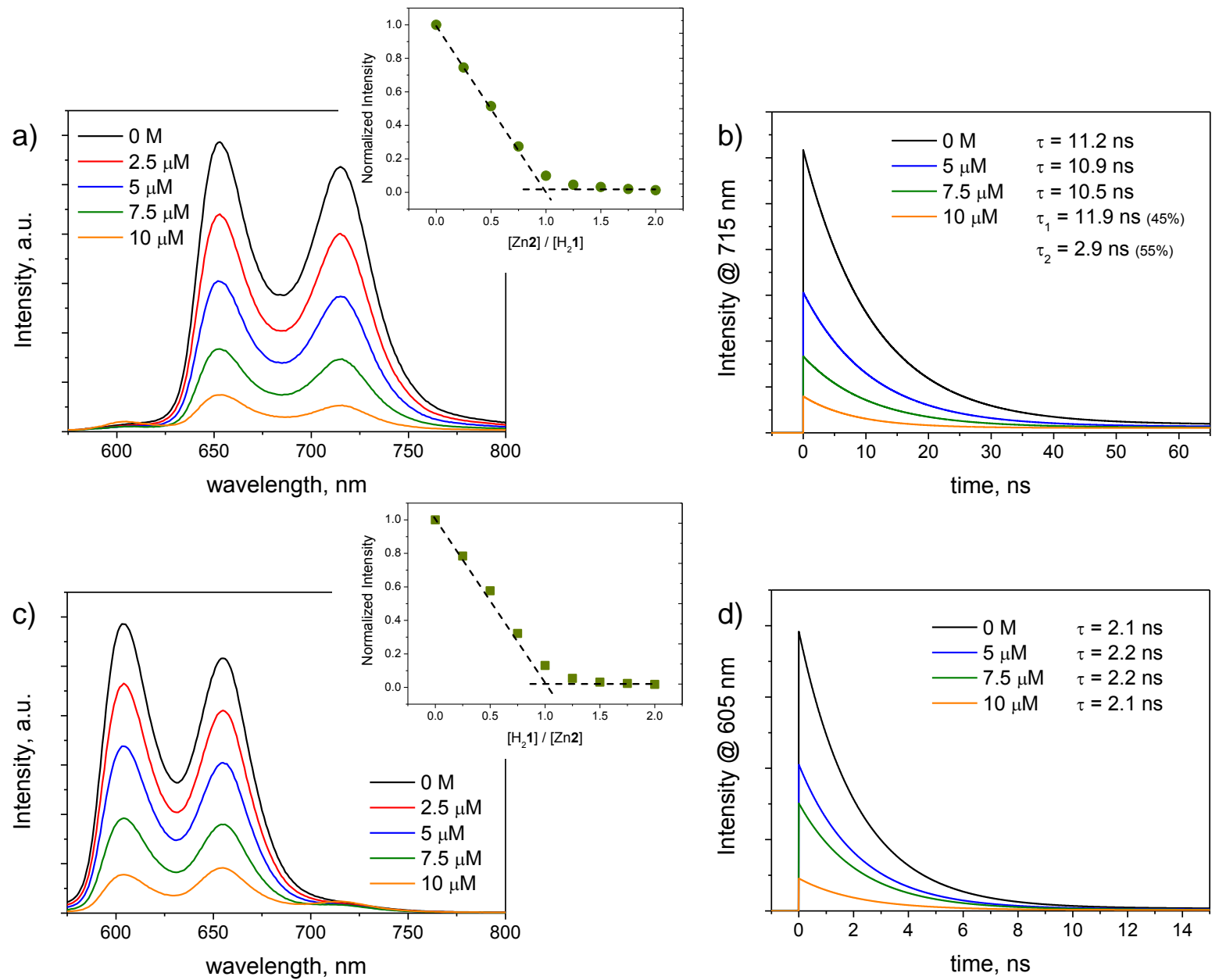

Figure S14. (a) Photoluminescence spectra (excitation at $502 \mathrm{~nm}$ ) and (b) time-resolved emission kinetics obtained by TC-SPC (excitation at $600 \mathrm{~nm}$, analysis at $715 \mathrm{~nm}$ ) of 50/50 THF/water mixtures containing $10 \mu \mathrm{M} \mathrm{H} \mathrm{H}_{2} \mathbf{1}$ and $0-10 \mu \mathrm{M}$ Zn2. Inset: emission titration curve obtained by

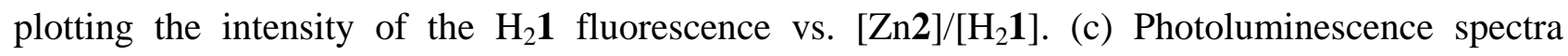
(excitation at $550 \mathrm{~nm}$ ) and (d) time-resolved emission kinetics obtained by TC-SPC (excitation at $600 \mathrm{~nm}$, analysis at $605 \mathrm{~nm}$ ) of 50/50 THF/water mixtures containing $10 \mu \mathrm{M} \mathrm{Zn2}$ and 0-10 $\mu \mathrm{M}$ $\mathrm{H}_{2}$ 1. Inset: emission titration curve obtained by plotting the intensity of the $\mathrm{Zn} 2$ fluorescence vs. $\left[\mathrm{H}_{2} 1\right] /[\mathrm{Zn} 2]$. In the emission titrations (insets) the fluorescence intensity is obtained from the emission spectra as the sole contribution of the spectrum of the titrated porphyrin according to spectral simulation. 

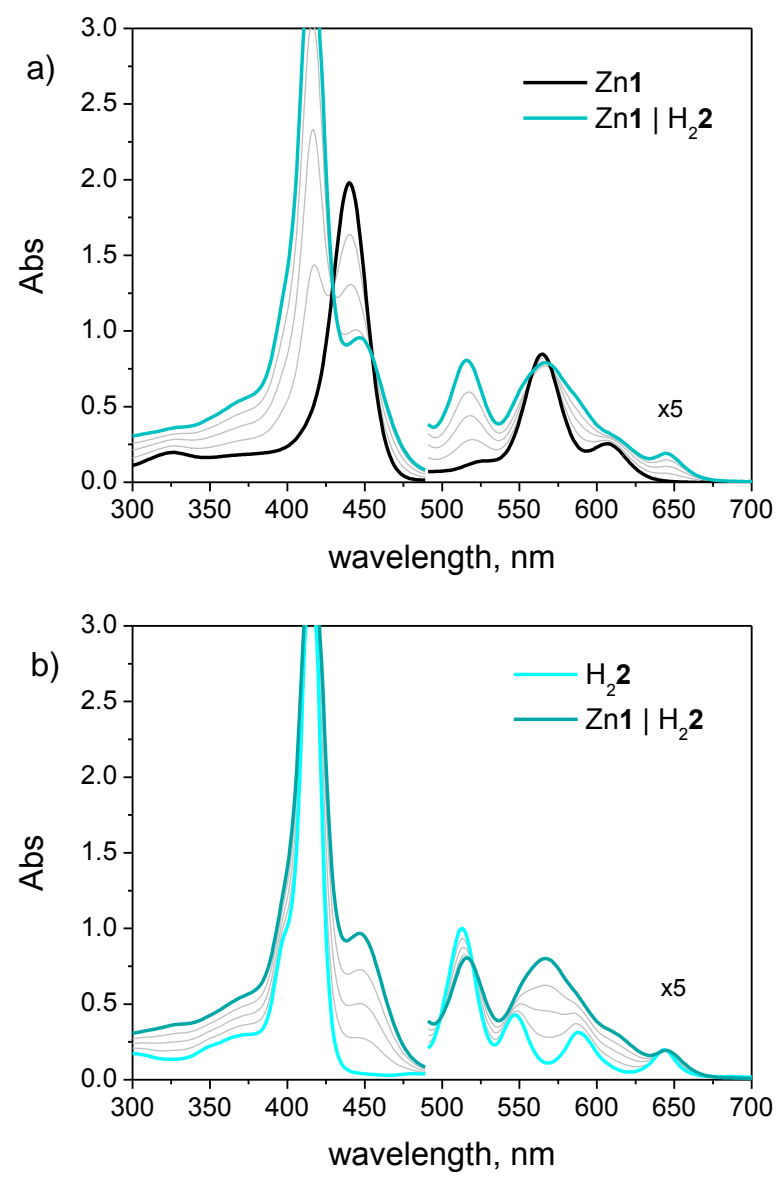

Figure S15. Spectrophotometric titration of (a) $10 \mu \mathrm{M} \mathrm{Zn} 1$ with $0-10 \mu \mathrm{M} \mathrm{H}_{2} 2$ (addition of $2.5 \mu \mathrm{M}$ amounts) and (b) $10 \mu \mathrm{M} \mathrm{H} \mathrm{H}_{2} 2$ with $0-10 \mu \mathrm{M} \mathrm{Zn1}$ (addition of $2.5 \mu \mathrm{M}$ amounts) in 50/50 ethanol/water. 

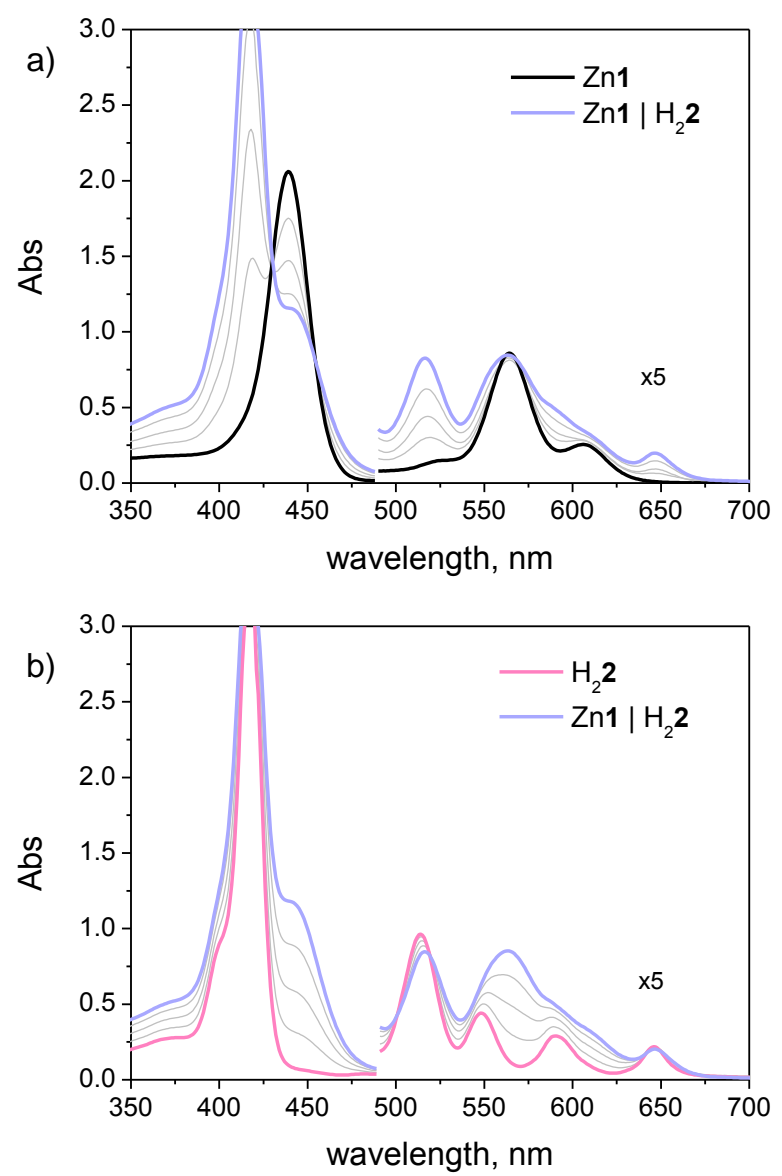

Figure S16. Spectrophotometric titration of (a) $10 \mu \mathrm{M} \mathrm{Zn} 1$ with $0-10 \mu \mathrm{M} \mathrm{H}_{2} 2$ (addition of $2.5 \mu \mathrm{M}$ amounts) and (b) $10 \mu \mathrm{M} \mathrm{H}_{2} 2$ with 0-10 $\mu \mathrm{M} \mathrm{Zn1} \mathrm{(addition} \mathrm{of} 2.5 \mu \mathrm{M}$ amounts) in 50/50 THF/water. 

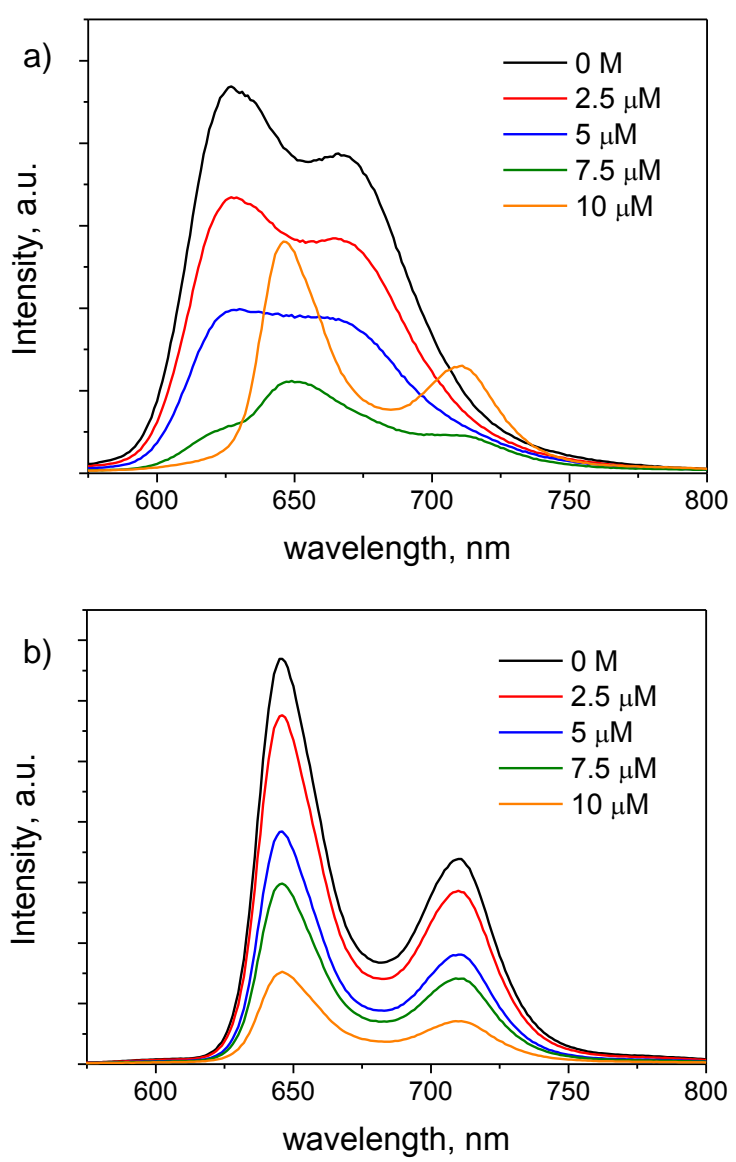

Figure S17. Photoluminescence spectra of 50/50 methanol/water mixtures containing (a) $10 \mu \mathrm{M}$ $\mathrm{Zn} 1$ and 0-10 $\mu \mathrm{M} \mathrm{H}_{2} 2$ (excitation at $555 \mathrm{~nm}$ ) or (b) $10 \mu \mathrm{M} \mathrm{H}_{2} 2$ and 0-10 $\mu \mathrm{M} \mathrm{Zn} 1$ (excitation at 499 $\mathrm{nm})$. 

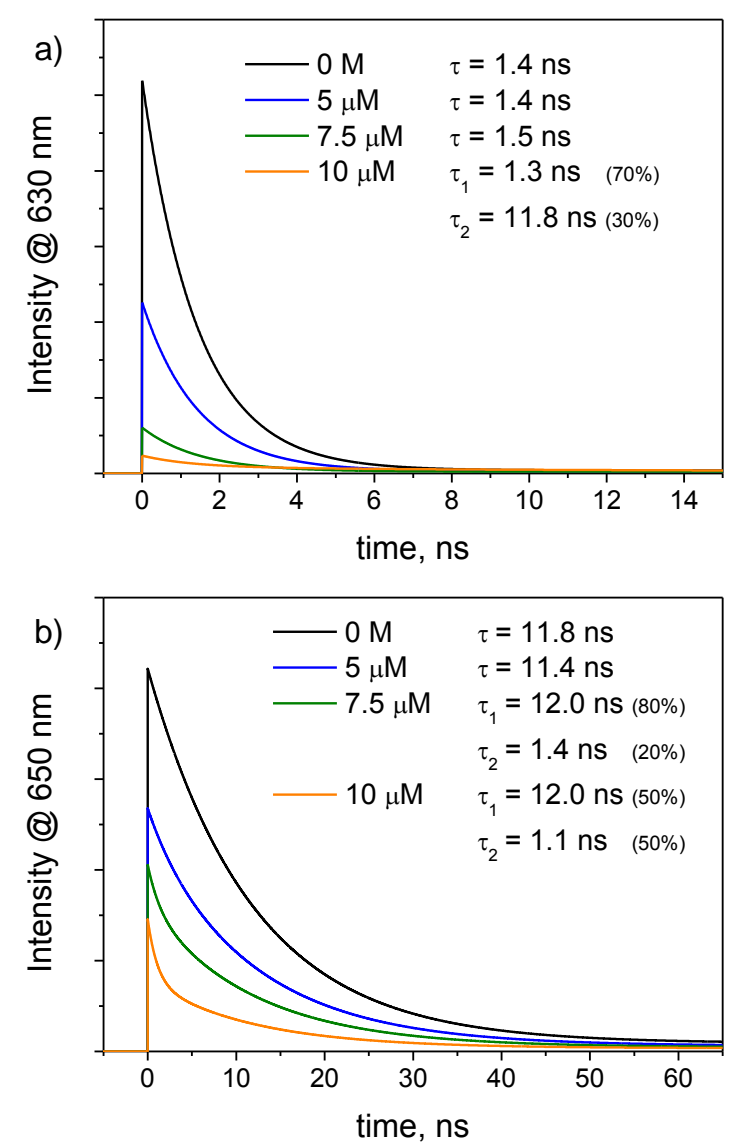

Figure S18. Time-resolved emission kinetics obtained by TC-SPC on 50/50 methanol/water mixtures containing (a) $10 \mu \mathrm{M} \mathrm{Zn1}$ and $0-10 \mu \mathrm{M} \mathrm{H} \mathrm{H}_{2} 2$ (excitation at $600 \mathrm{~nm}$, analysis at $630 \mathrm{~nm}$ ) or (b) $10 \mu \mathrm{M} \mathrm{H}_{2} 2$ and $0-10 \mu \mathrm{M} \mathrm{Zn1}$ (excitation at $600 \mathrm{~nm}$, analysis at $650 \mathrm{~nm}$ ). 

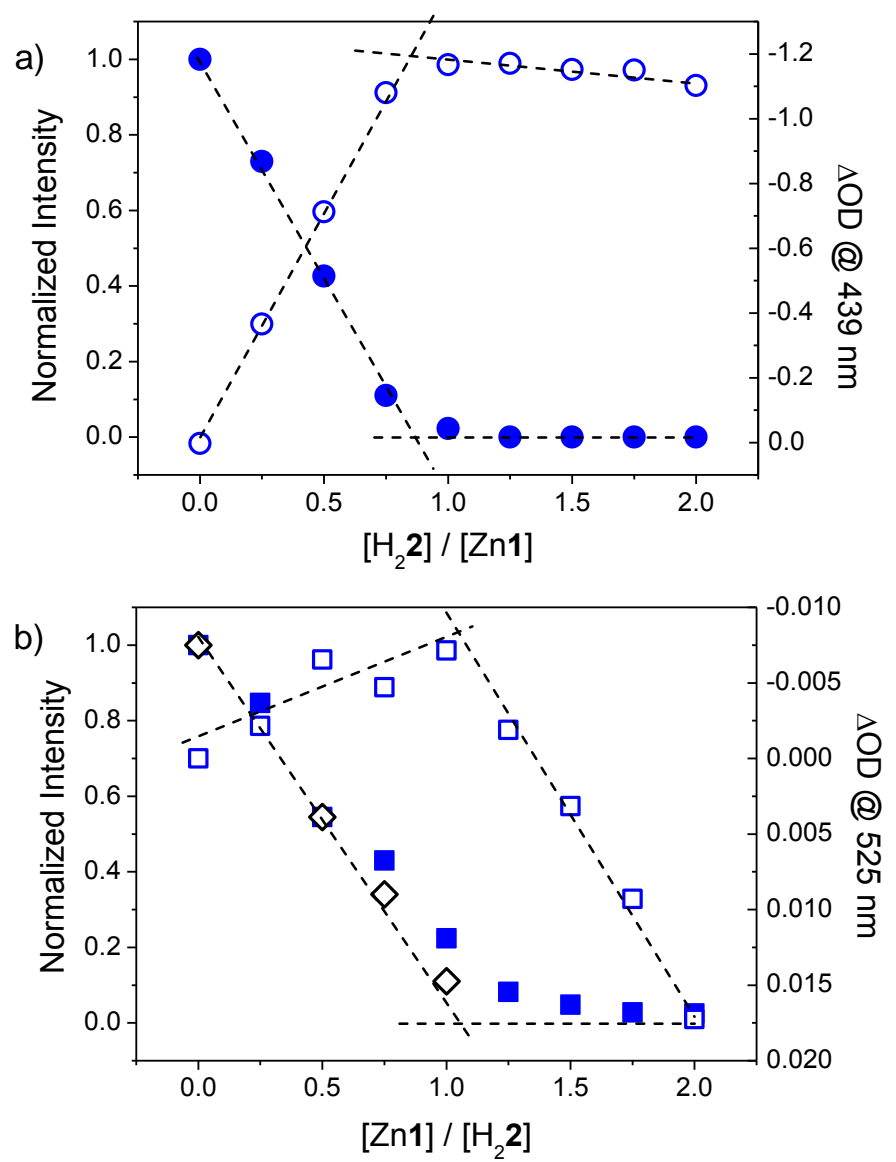

Figure S19. (a) Spectrophotometric (empty dots) and emission (full dots) titration of $10 \mu \mathrm{M} \mathrm{Zn1}$ with $\mathrm{H}_{2} 2$ in 50/50 methanol/water and (b) spectrophotometric (empty squares) and emission (full squares) titration of $10 \mu \mathrm{M} \mathrm{H}_{2} 2$ with $\mathrm{Zn} 1$ in 50/50 methanol/water. In the emission titrations the fluorescence intensity is obtained from the emission spectra (Figure S17) as the sole contribution of the spectrum of the titrated porphyrin according to spectral simulation. In (b), the black empty diamonds represent the sole contribution of non-associated species to the $\mathrm{H}_{2} 2$ emission, as obtained from the pre-exponential factors of the long-lived (12 ns) component. 

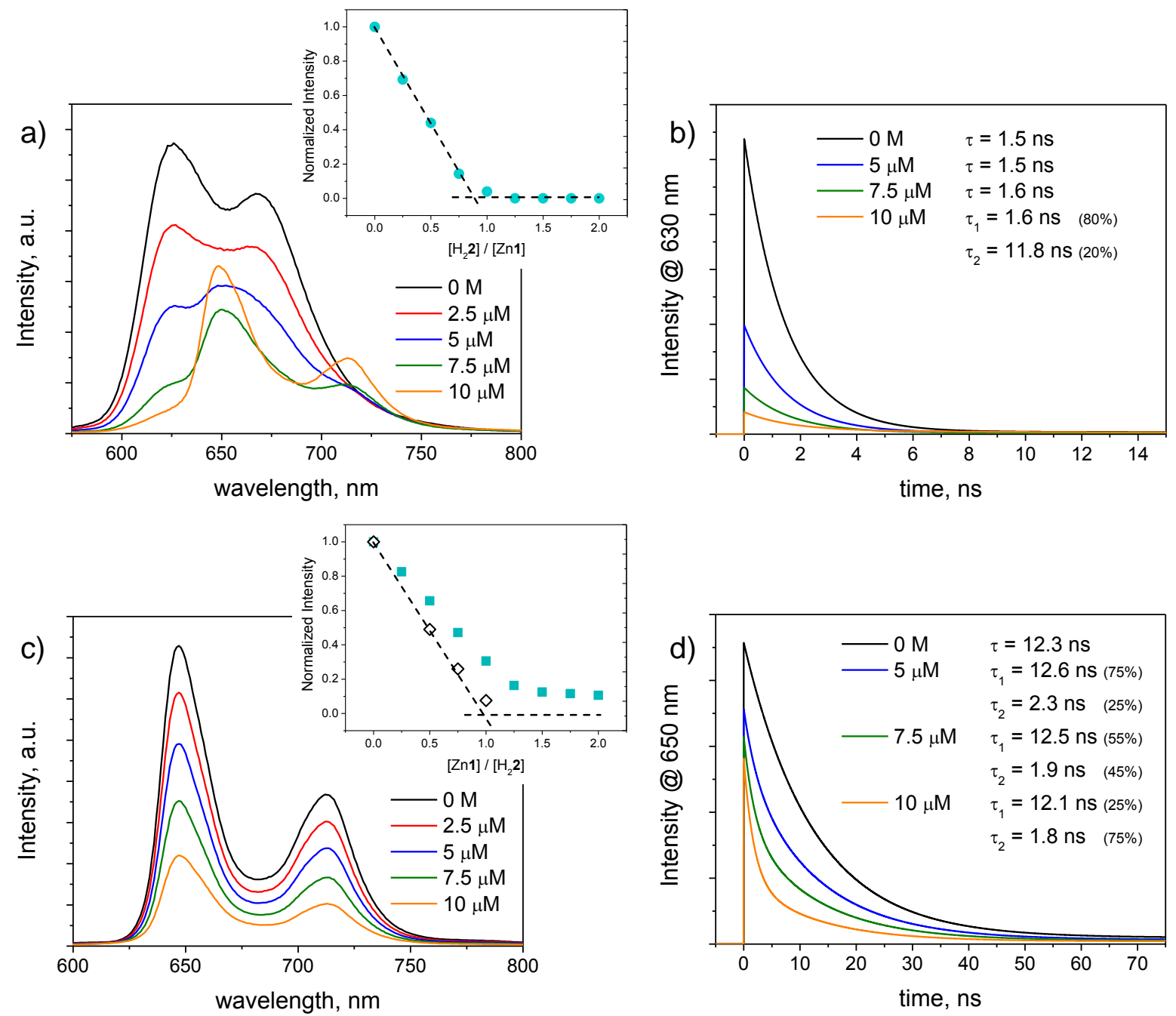

Figure S20. (a) Photoluminescence spectra (excitation at $557 \mathrm{~nm}$ ) and (b) time-resolved emission kinetics obtained by TC-SPC (excitation at $600 \mathrm{~nm}$, analysis at $630 \mathrm{~nm}$ ) of 50/50 ethanol/water mixtures containing $10 \mu \mathrm{M} \mathrm{Zn1}$ and $0-10 \mu \mathrm{M} \mathrm{H} \mathrm{H}_{2}$. Inset: emission titration curve obtained by plotting the intensity of the $\mathrm{Zn1}$ fluorescence vs. $\left[\mathrm{H}_{2} 2\right] /[\mathrm{Zn1}]$. (c) Photoluminescence spectra (excitation at $498 \mathrm{~nm}$ ) and (d) time-resolved emission kinetics obtained by TC-SPC (excitation at $600 \mathrm{~nm}$, analysis at $650 \mathrm{~nm}$ ) of 50/50 ethanol/water mixtures containing $10 \mu \mathrm{M} \mathrm{H}_{2} 2$ and 0-10 $\mu \mathrm{M}$ Zn1. Inset: uncorrected (full squares) and corrected (empty diamonds) emission titration curves obtained by plotting the intensity of the $\mathrm{H}_{2} 2$ fluorescence vs. [ $\left.\mathrm{Zn} 1\right] /\left[\mathrm{H}_{2} 2\right]$. In the emission titrations (insets) the fluorescence intensity is obtained from the emission spectra as the sole contribution of the spectrum of the titrated porphyrin according to spectral simulation. 

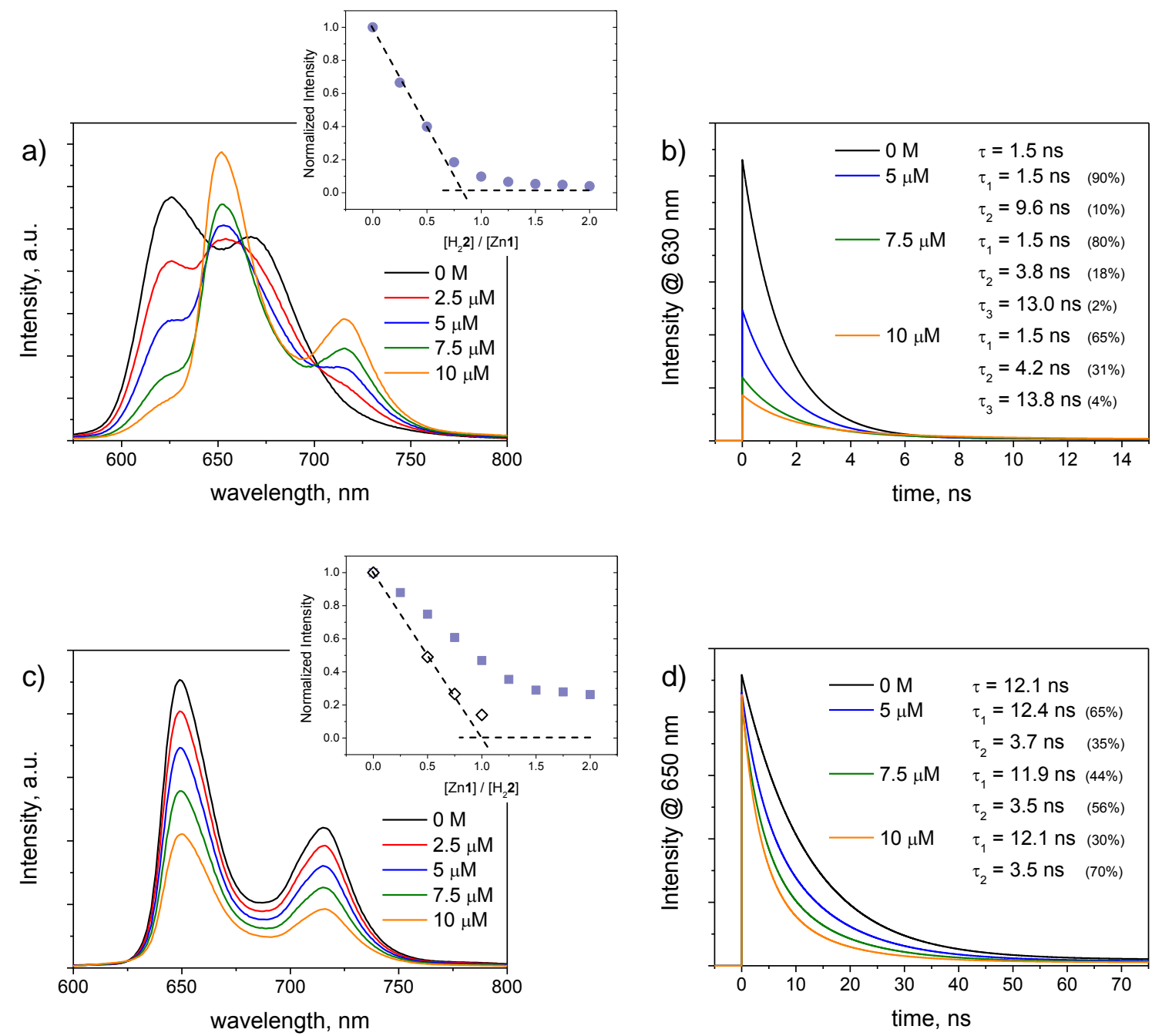

Figure S21. (a) Photoluminescence spectra (excitation at $558 \mathrm{~nm}$ ) and (b) time-resolved emission kinetics obtained by TC-SPC (excitation at $600 \mathrm{~nm}$, analysis at $630 \mathrm{~nm}$ ) of 50/50 THF/water mixtures containing $10 \mu \mathrm{M} \mathrm{Zn} 1$ and $0-10 \mu \mathrm{M} \mathrm{H} \mathrm{H}_{2}$. Inset: emission titration curve obtained by plotting the intensity of the $\mathrm{Zn1}$ fluorescence vs. $\left[\mathrm{H}_{2} 2\right] /[\mathrm{Zn1}]$. (c) Photoluminescence spectra (excitation at $500 \mathrm{~nm}$ ) and (d) time-resolved emission kinetics obtained by TC-SPC (excitation at $600 \mathrm{~nm}$, analysis at $650 \mathrm{~nm}$ ) of 50/50 THF/water mixtures containing $10 \mu \mathrm{M} \mathrm{H}_{2} 2$ and $0-10 \mu \mathrm{M}$ Zn1. Inset: uncorrected (full squares) and corrected (empty diamonds) emission titration curves obtained by plotting the intensity of the $\mathrm{H}_{2} 2$ fluorescence vs. [ $\left.\mathrm{Zn} 1\right] /\left[\mathrm{H}_{2} 2\right]$. In the emission titrations (insets) the fluorescence intensity is obtained from the emission spectra as the sole contribution of the spectrum of the titrated porphyrin according to spectral simulation. 

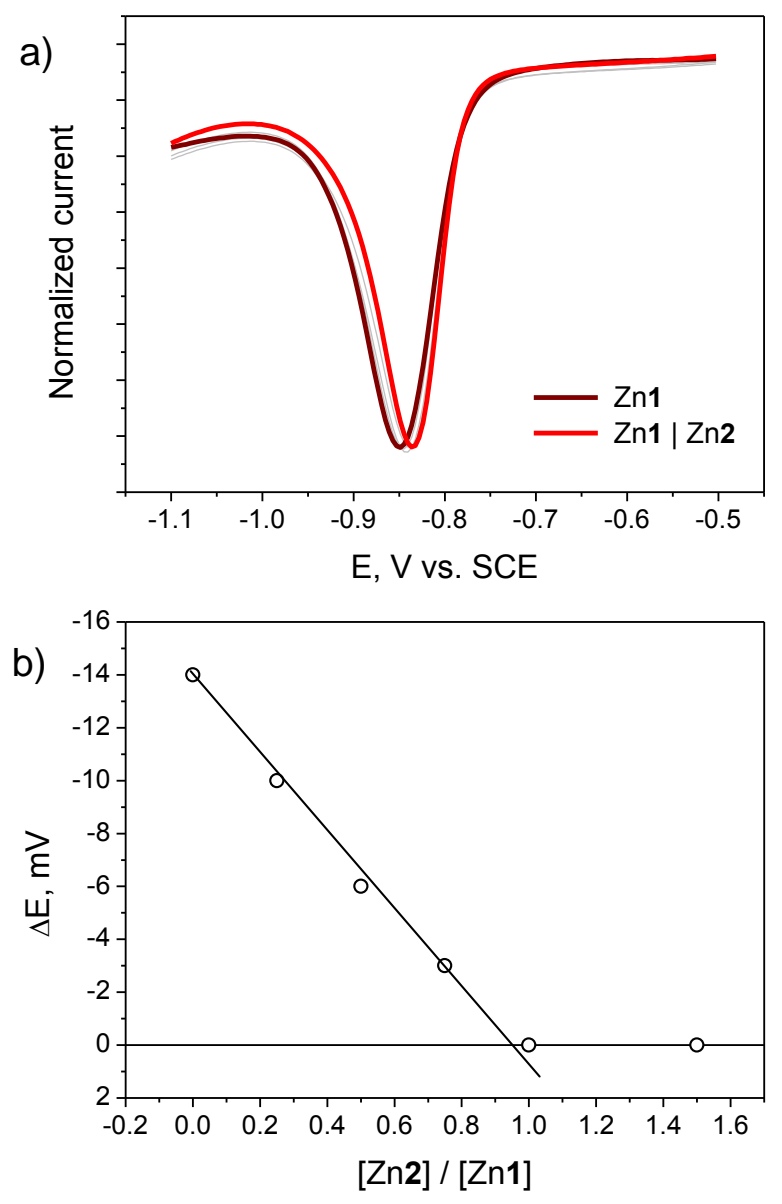

Figure S22. (a) Differential pulse voltammetry (DPV) of 50/50 methanol/water solutions (0.1 M $\mathrm{Li}_{2} \mathrm{SO}_{4}$ ) containing $0.1 \mathrm{mM} \mathrm{Zn1}$ and $0-0.15 \mathrm{mM} \mathrm{Zn2}$; (b) plot of the potential shift vs. the Zn2-toZn1 ratio. 

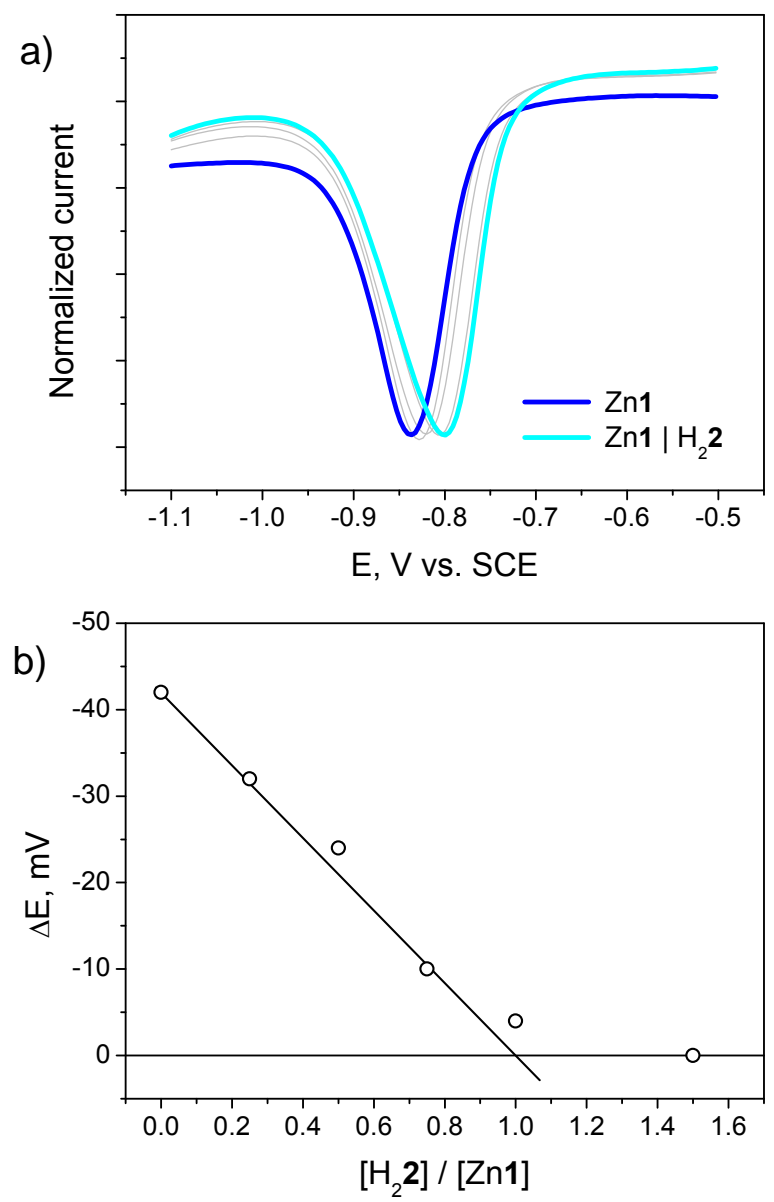

Figure S23. (a) Differential pulse voltammetry (DPV) of 50/50 methanol/water solutions (0.1 M $\mathrm{Li}_{2} \mathrm{SO}_{4}$ ) containing $0.1 \mathrm{mM} \mathrm{Zn1}$ and $0-0.15 \mathrm{mM} \mathrm{H}_{2}$; (b) plot of the potential shift vs. the $\mathrm{H}_{2}$ 2-to$\mathrm{Zn} 1$ ratio. 

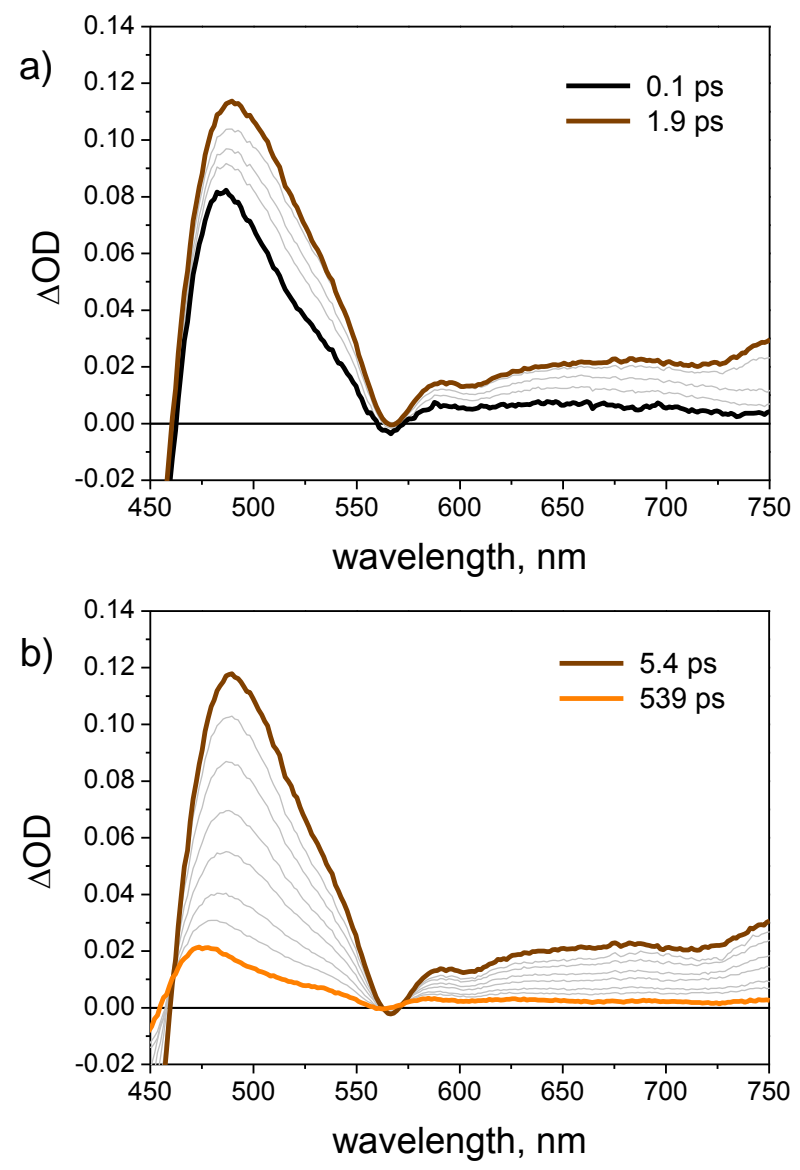

Figure S24. Transient absorption spectra obtained by ultrafast spectroscopy (excitation at $400 \mathrm{~nm}$ ) on a 50/50 ethanol/water solution containing $50 \mu \mathrm{M} Z \mathrm{Zn} 1$ and $50 \mu \mathrm{M} \mathrm{Zn} 2$ between (a) 0.1-1.9 ps and (b) 5.4-539 ps time-delays. 

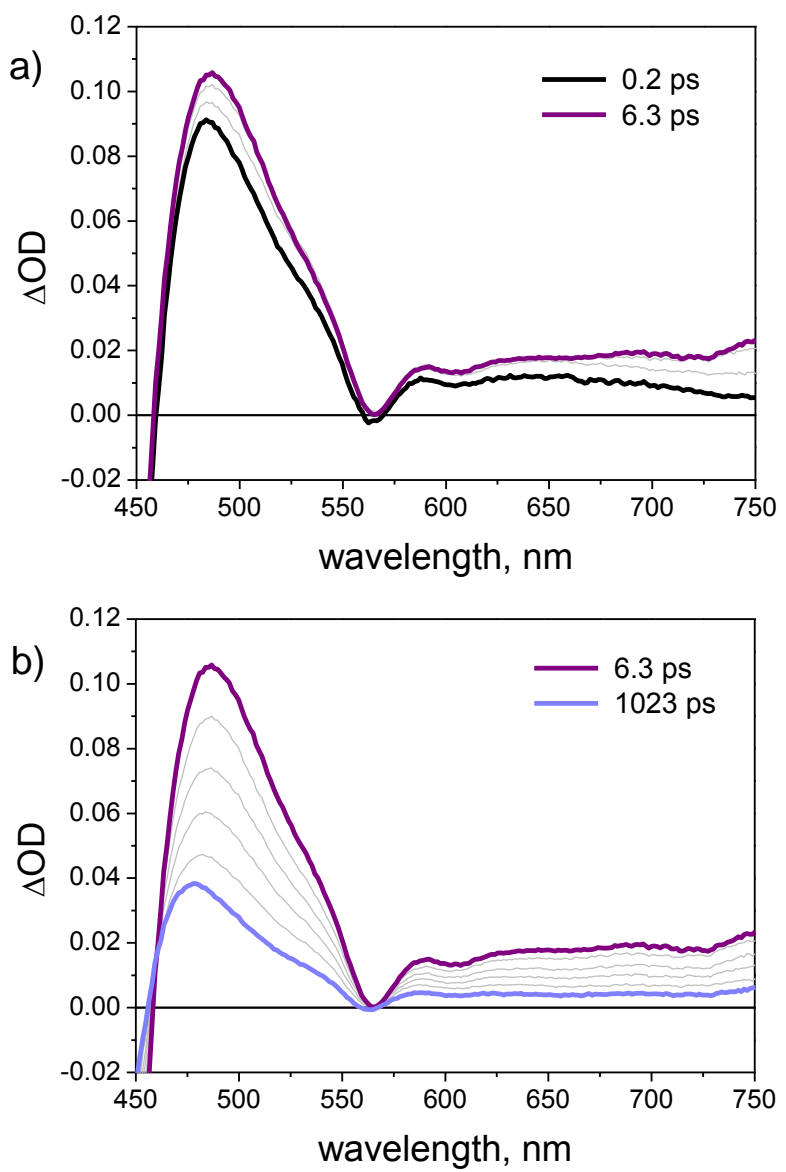

Figure S25. Transient absorption spectra obtained by ultrafast spectroscopy (excitation at $400 \mathrm{~nm}$ ) on a $50 / 50 \mathrm{THF} /$ water solution containing $50 \mu \mathrm{M} \mathrm{Zn} 1$ and $50 \mu \mathrm{M} \mathrm{Zn} 2$ between (a) 0.2-6.3 ps and (b) 6.3-1023 ps time-delays. 

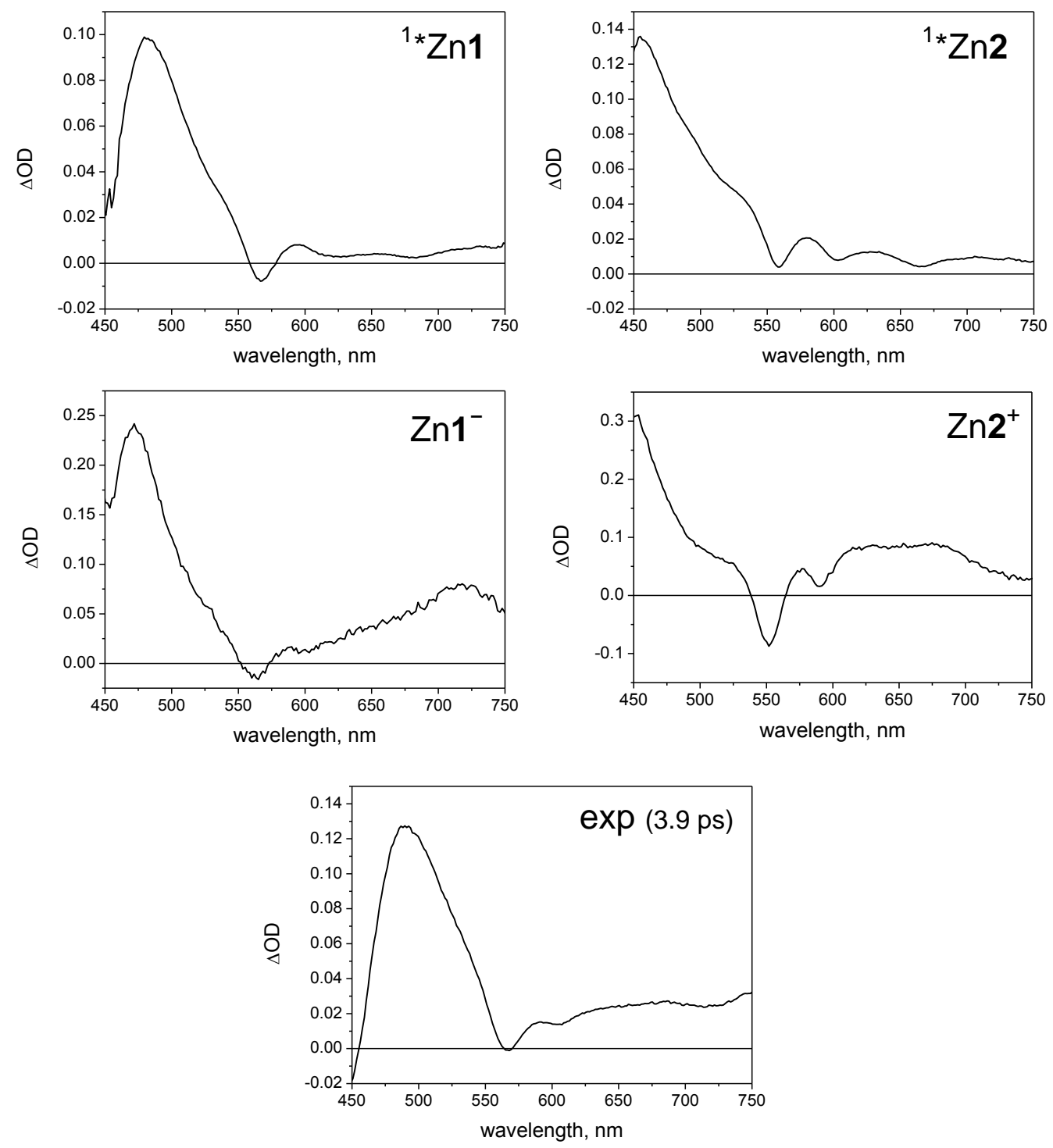

Figure S26. Comparison between the difference absorption spectra of the $\mathrm{Zn} \mathbf{1}$ and $\mathrm{Zn} 2$ singlet excited state (obtained by ultrafast spectroscopy of the Zn1 and Zn2 monomers), Zn1 radical anion (obtained by flash photolysis of a $\mathrm{Zn} 1$ solution in the presence of $0.01 \mathrm{M}$ ascorbic acid), $\mathrm{Zn} 2$ radical cation (obtained by flash photolysis of a $\mathrm{Zn} 2$ solution in the presence of $1 \mathrm{mM} \mathrm{Co}\left(\mathrm{NH}_{3}\right)_{5} \mathrm{Cl}_{2}$ ) and the experimental spectrum at 3.9 ps time-delay from the ultrafast spectroscopy of the $\mathrm{Zn} \mathbf{1} \mid \mathrm{Zn} \mathbf{2}$ ionpair in 50/50 methanol/water (see Figure 6 of the main text). 

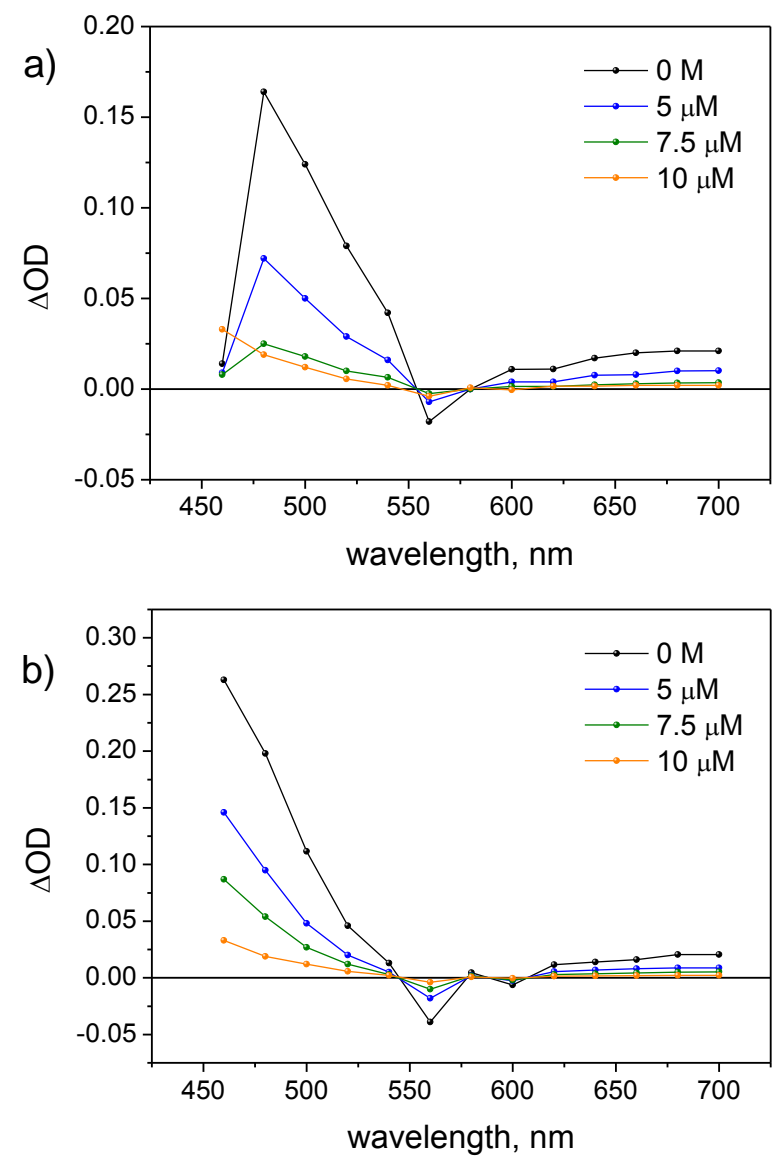

Figure S27. Transient absorption spectra at $15 \mathrm{~ns}$ time delay obtained by laser flash photolysis (excitation at $532 \mathrm{~nm}$ ) in 50/50 methanol/water solutions containing (a) $10 \mu \mathrm{M} \mathrm{Zn} 1$ and $0-10 \mu \mathrm{M}$ $\mathrm{Zn} 2$ or (a) $10 \mu \mathrm{M} \mathrm{Zn} 2$ and $0-10 \mu \mathrm{M} \mathrm{Zn} 1$. The spectra correspond to the transient spectra of the triplet excited state of (a) Zn1 or (b) Zn2 whose decrease in intensity parallels the trend of the emission intensity (Figure S4) upon addition of different amounts of Zn2 or Zn1, respectively. 

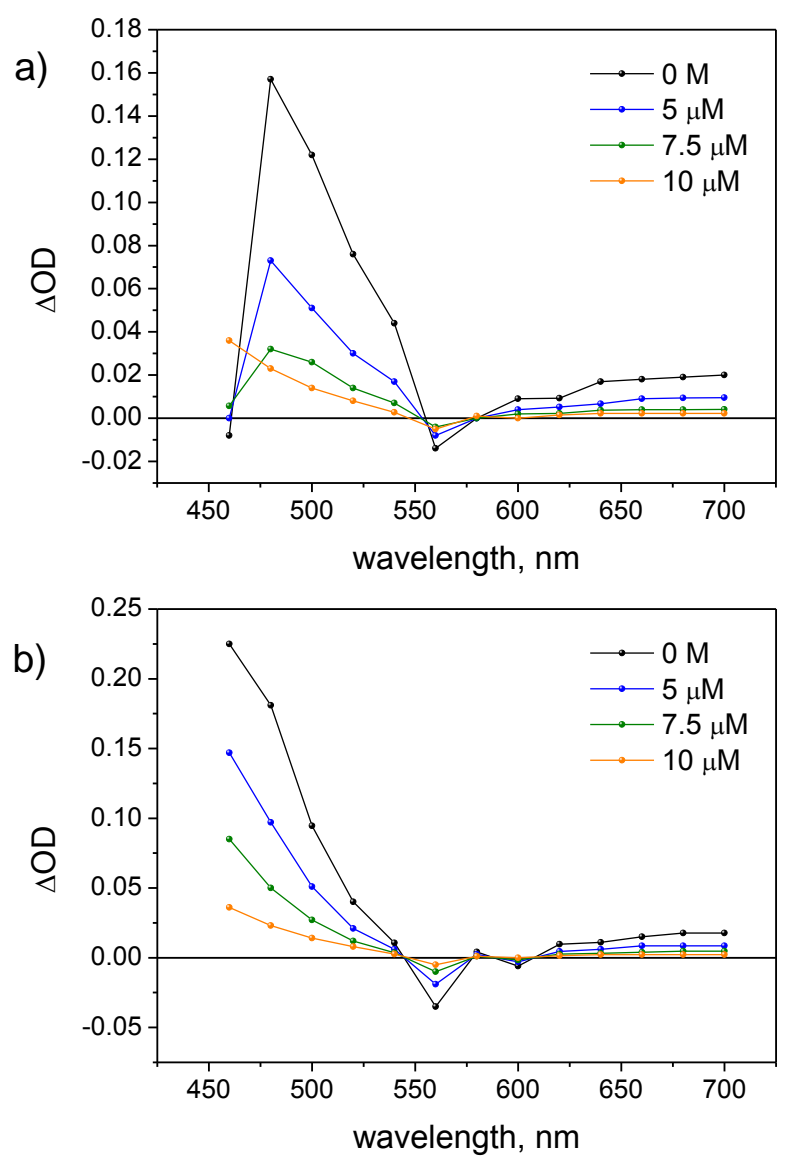

Figure S28. Transient absorption spectra at $15 \mathrm{~ns}$ time delay obtained by laser flash photolysis (excitation at $532 \mathrm{~nm}$ ) in 50/50 ethanol/water solutions containing (a) $10 \mu \mathrm{M} \mathrm{Zn1}$ and 0-10 $\mu \mathrm{M}$ Zn2

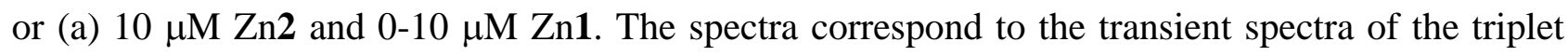
excited state of (a) $\mathrm{Zn} 1$ or (b) $\mathrm{Zn} 2$ whose decrease in intensity parallels the trend of the emission intensity (Figure S6) upon addition of different amounts of $\mathrm{Zn} 2$ or Zn1, respectively. 

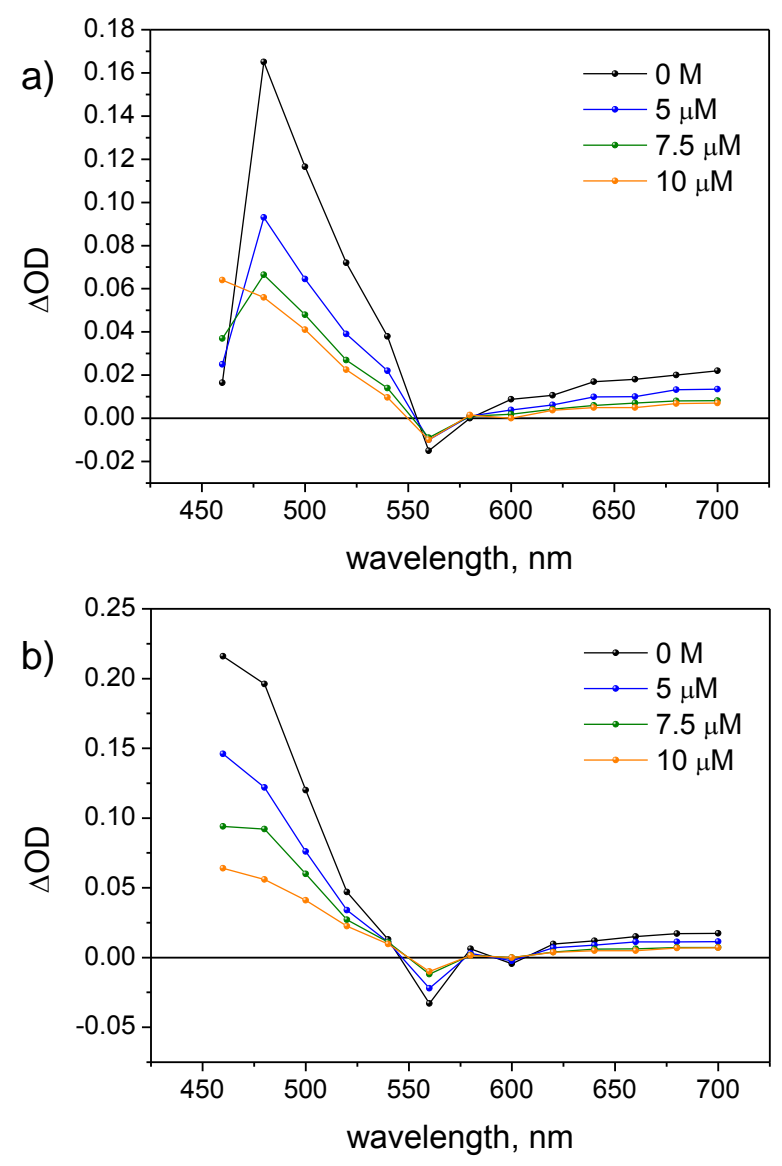

Figure S29. Transient absorption spectra at $15 \mathrm{~ns}$ time delay obtained by laser flash photolysis (excitation at $532 \mathrm{~nm}$ ) in 50/50 THF/water solutions containing (a) $10 \mu \mathrm{M} Z \mathrm{Zn} \mathbf{1}$ and 0-10 $\mu \mathrm{M} \mathrm{Zn} 2$ or (a) $10 \mu \mathrm{M} Z \mathrm{Zn} 2$ and $0-10 \mu \mathrm{M} \mathrm{Zn1}$. The spectra correspond to the transient spectra of the triplet excited state of (a) Zn1 or (b) Zn2 whose decrease in intensity parallels the trend of the emission intensity (Figure S7) upon addition of different amounts of Zn2 or Zn1, respectively. 

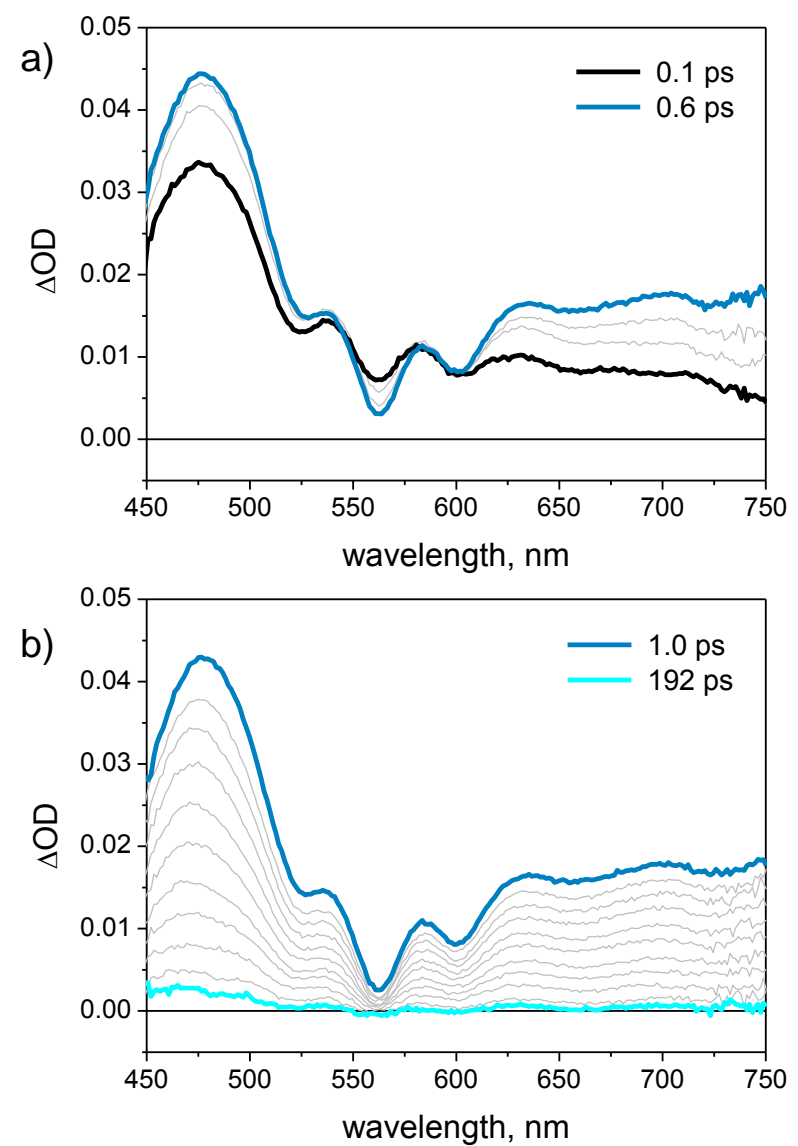

Figure S30. Transient absorption spectra obtained by ultrafast spectroscopy (excitation at $400 \mathrm{~nm}$ ) on a $50 / 50$ ethanol/water solution containing $50 \mu \mathrm{M} \mathrm{H}_{2} \mathbf{1}$ and $50 \mu \mathrm{M} \mathrm{Zn2}$ between (a) 0.1-0.6 ps and (b) 1.0-192 ps time-delays. 

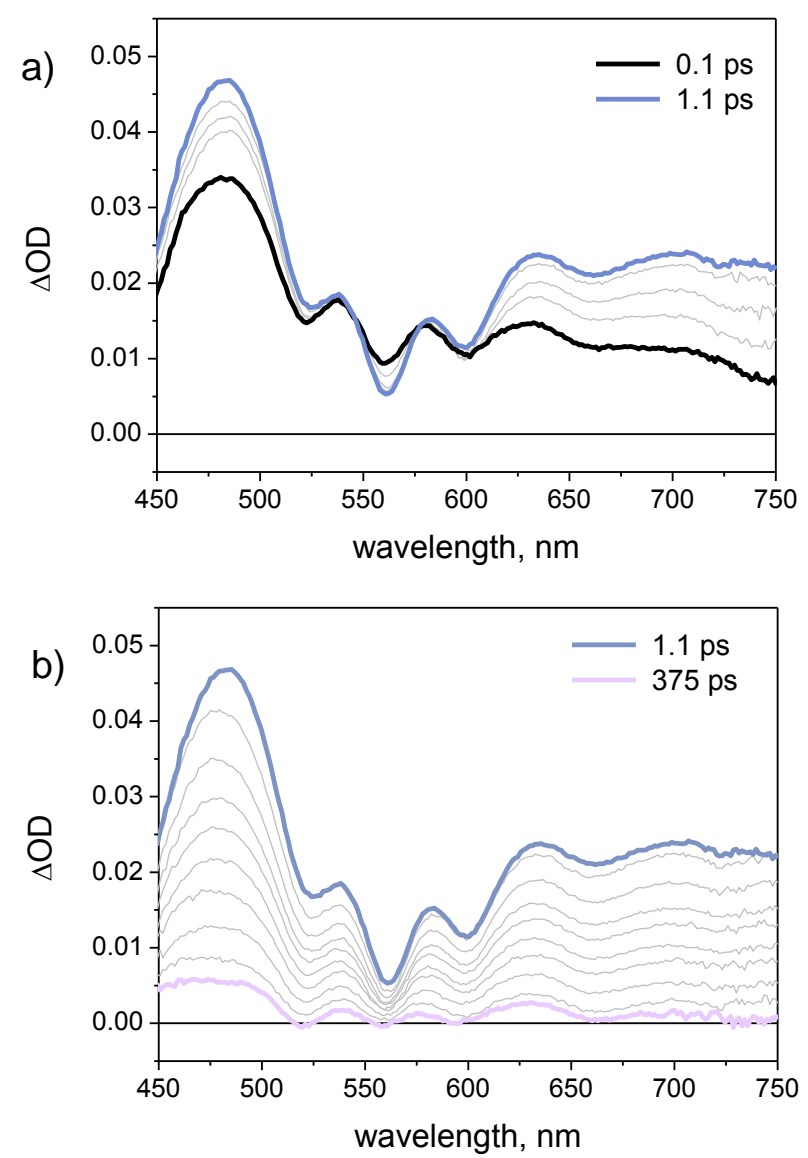

Figure S31. Transient absorption spectra obtained by ultrafast spectroscopy (excitation at $400 \mathrm{~nm}$ ) on a $50 / 50 \mathrm{THF} /$ water solution containing $50 \mu \mathrm{M} \mathrm{H} \mathrm{H}_{2} 1$ and $50 \mu \mathrm{M} \mathrm{Zn} 2$ between (a) 0.1-1.1 ps and (b) 1.1-375 ps time-delays. 

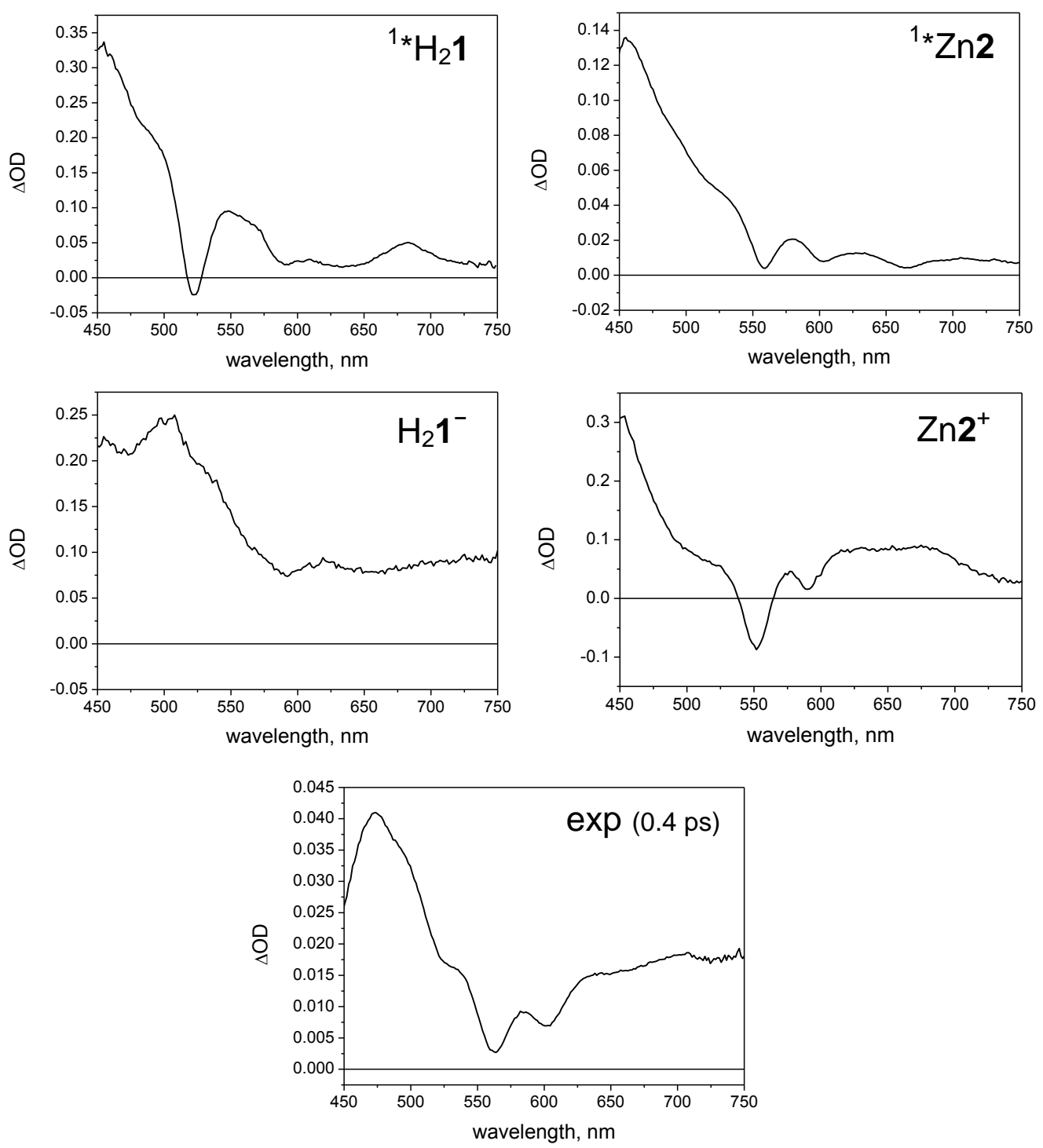

Figure S32. Comparison between the difference absorption spectra of the $\mathrm{H}_{2} \mathbf{1}$ and $\mathrm{Zn} 2$ singlet excited state (obtained by ultrafast spectroscopy of the $\mathrm{H}_{2} \mathbf{1}$ and $\mathrm{Zn} 2$ monomers), $\mathrm{H}_{2} \mathbf{1}$ radical anion (obtained by flash photolysis of a $\mathrm{H}_{2} \mathbf{1}$ solution in the presence of $0.01 \mathrm{M}$ ascorbic acid), $\mathrm{Zn} 2$ radical cation (obtained by flash photolysis of a $\mathrm{Zn} 2$ solution in the presence of $1 \mathrm{mM} \mathrm{Co}\left(\mathrm{NH}_{3}\right)_{5} \mathrm{Cl}_{2}$ ) and the experimental spectrum at 0.4 ps time-delay from the ultrafast spectroscopy of the $\mathrm{H}_{2} \mathbf{1} \mid \mathrm{Zn} 2$ ionpair in 50/50 methanol/water (see Figure 9 of the main text). 

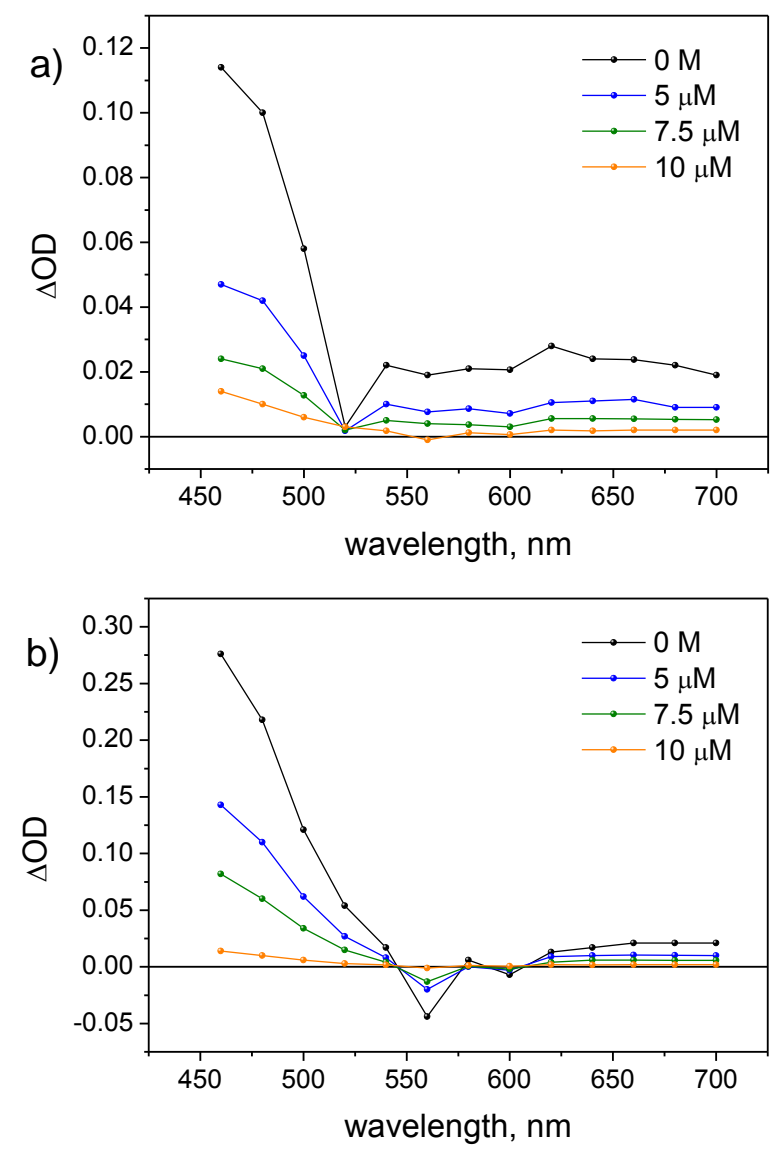

Figure S33. Transient absorption spectra at $15 \mathrm{~ns}$ time delay obtained by laser flash photolysis (excitation at $532 \mathrm{~nm}$ ) in 50/50 methanol/water solutions containing (a) $10 \mu \mathrm{M} \mathrm{H} \mathrm{H}_{2} \mathbf{1}$ and $0-10 \mu \mathrm{M}$ $\mathrm{Zn} 2$ or (a) $10 \mu \mathrm{M} \mathrm{Zn} 2$ and $0-10 \mu \mathrm{M} \mathrm{H} \mathrm{H}_{2}$. The spectra correspond to the transient spectra of the triplet excited state of (a) $\mathrm{H}_{2} \mathbf{1}$ or (b) $\mathrm{Zn} 2$ whose decrease in intensity parallels the trend of the emission intensity (Figure S10) upon addition of different amounts of $\mathrm{Zn} \mathbf{2}$ or $\mathrm{H}_{2} \mathbf{1}$, respectively. 

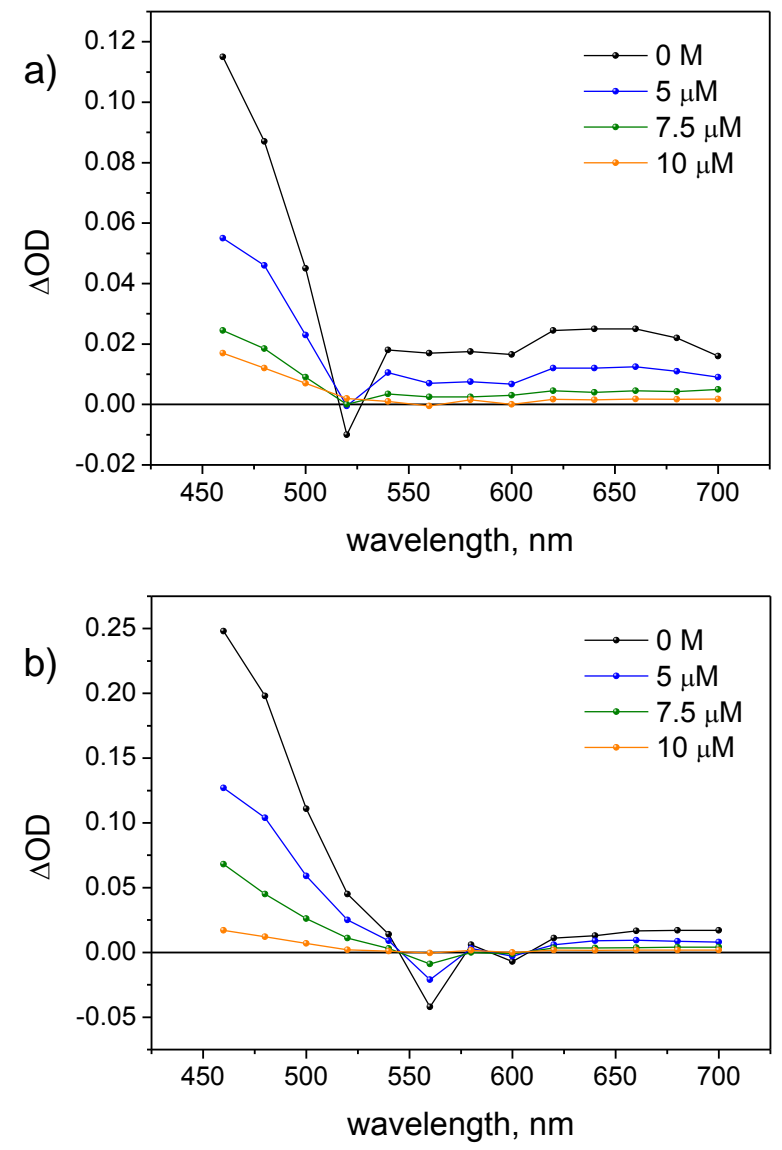

Figure S34. Transient absorption spectra at $15 \mathrm{~ns}$ time delay obtained by laser flash photolysis (excitation at $532 \mathrm{~nm}$ ) in 50/50 ethanol/water solutions containing (a) $10 \mu \mathrm{M} \mathrm{H}_{2} \mathbf{1}$ and 0-10 $\mu \mathrm{M} \mathrm{Zn2}$ or (a) $10 \mu \mathrm{M} \mathrm{Zn} 2$ and $0-10 \mu \mathrm{M} \mathrm{H}_{2} 1$. The spectra correspond to the transient spectra of the triplet excited state of (a) $\mathrm{H}_{2} \mathbf{1}$ or (b) $\mathrm{Zn} 2$ whose decrease in intensity parallels the trend of the emission intensity (Figure S12) upon addition of different amounts of $\mathrm{Zn} 2$ or $\mathrm{H}_{2} \mathbf{1}$, respectively. 

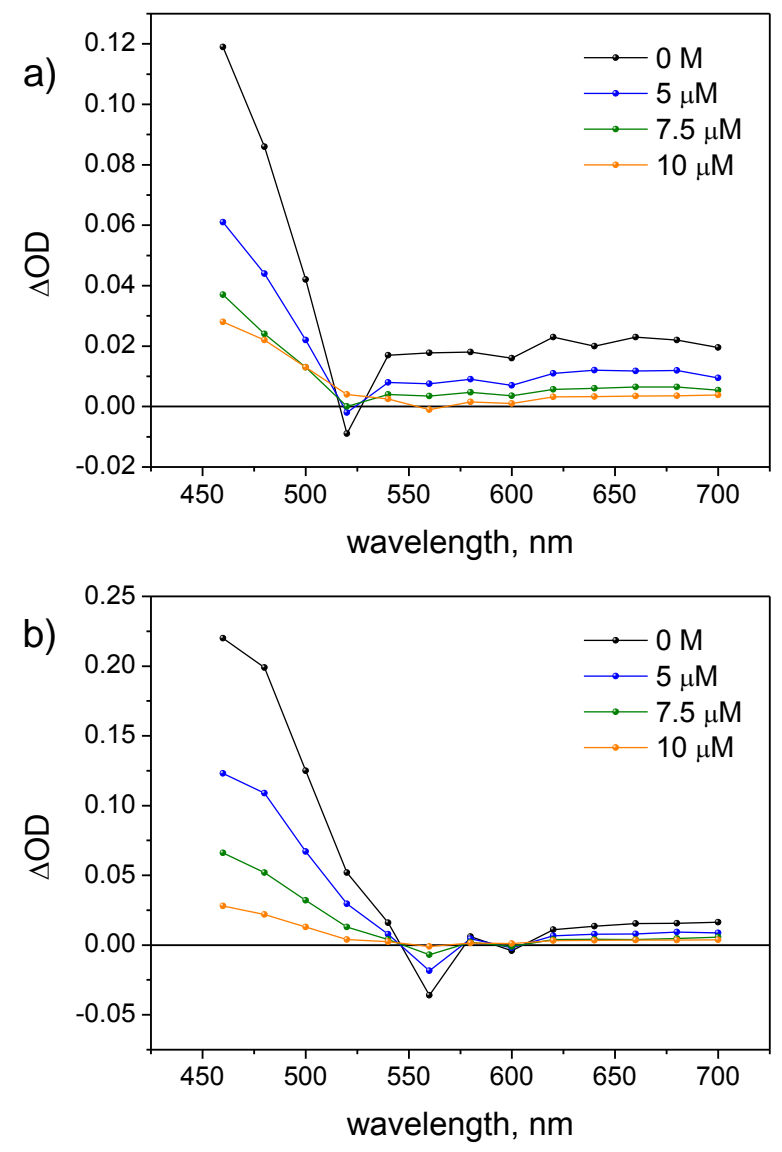

Figure S35. Transient absorption spectra at 15 ns time delay obtained by laser flash photolysis (excitation at $532 \mathrm{~nm}$ ) in 50/50 THF/water solutions containing (a) $10 \mu \mathrm{M} \mathrm{H}_{2} \mathbf{1}$ and 0-10 $\mu \mathrm{M} \mathrm{Zn} 2$ or (a) $10 \mu \mathrm{M} \mathrm{Zn} 2$ and $0-10 \mu \mathrm{M} \mathrm{H}_{2}$. The spectra correspond to the transient spectra of the triplet excited state of (a) $\mathrm{H}_{2} \mathbf{1}$ or (b) $\mathrm{Zn} 2$ whose decrease in intensity parallels the trend of the emission intensity (Figure S13) upon addition of different amounts of $\mathrm{Zn} 2$ or $\mathrm{H}_{2} \mathbf{1}$, respectively. 
a)

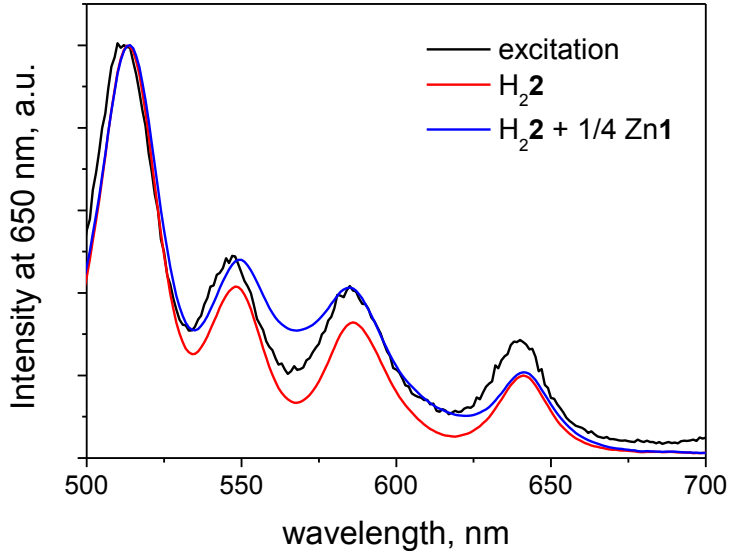

b)

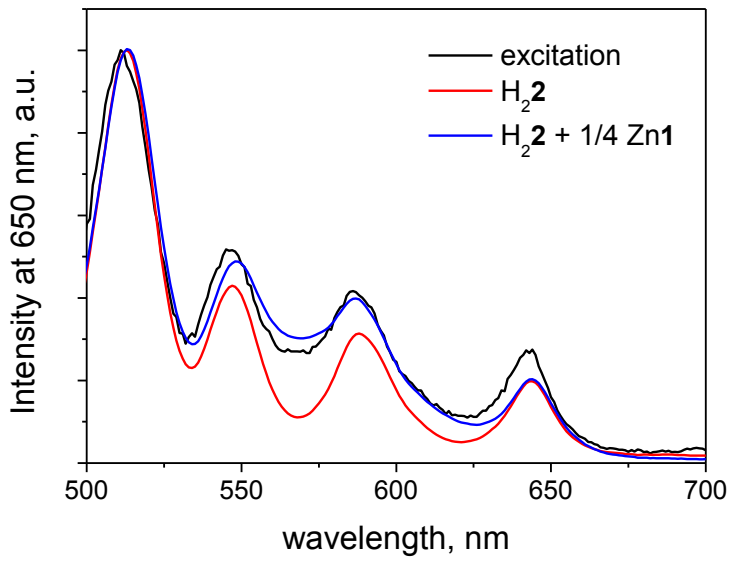

c)

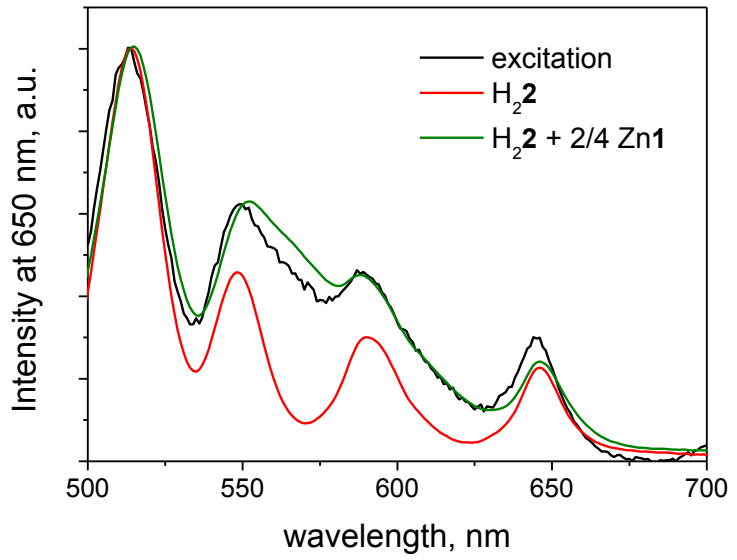

Figure S36. Excitation spectra (black traces) of the emission of $\mathrm{H}_{2} 2$ at $650 \mathrm{~nm}$ obtained on (a) 50/50 methanol/water, (b) 50/50 ethanol/water, and (c) 50/50 THF/water solutions containing 10 $\mu \mathrm{M} \mathrm{Zn1}$ and $10 \mu \mathrm{M} \mathrm{H}_{2} 2$. For the estimation of the energy transfer efficiencies the normalized absorption spectra of $10 \mu \mathrm{M} \mathrm{H}_{2} 2$ (red traces) and of $10 \mu \mathrm{M} \mathrm{H_{2 } 2}$ in the presence of $2.5 \mu \mathrm{M} \mathrm{Zn} 1$ (blue traces) or $5 \mu \mathrm{M} \mathrm{Zn} \mathbf{1}$ (green traces) have been also compared. 

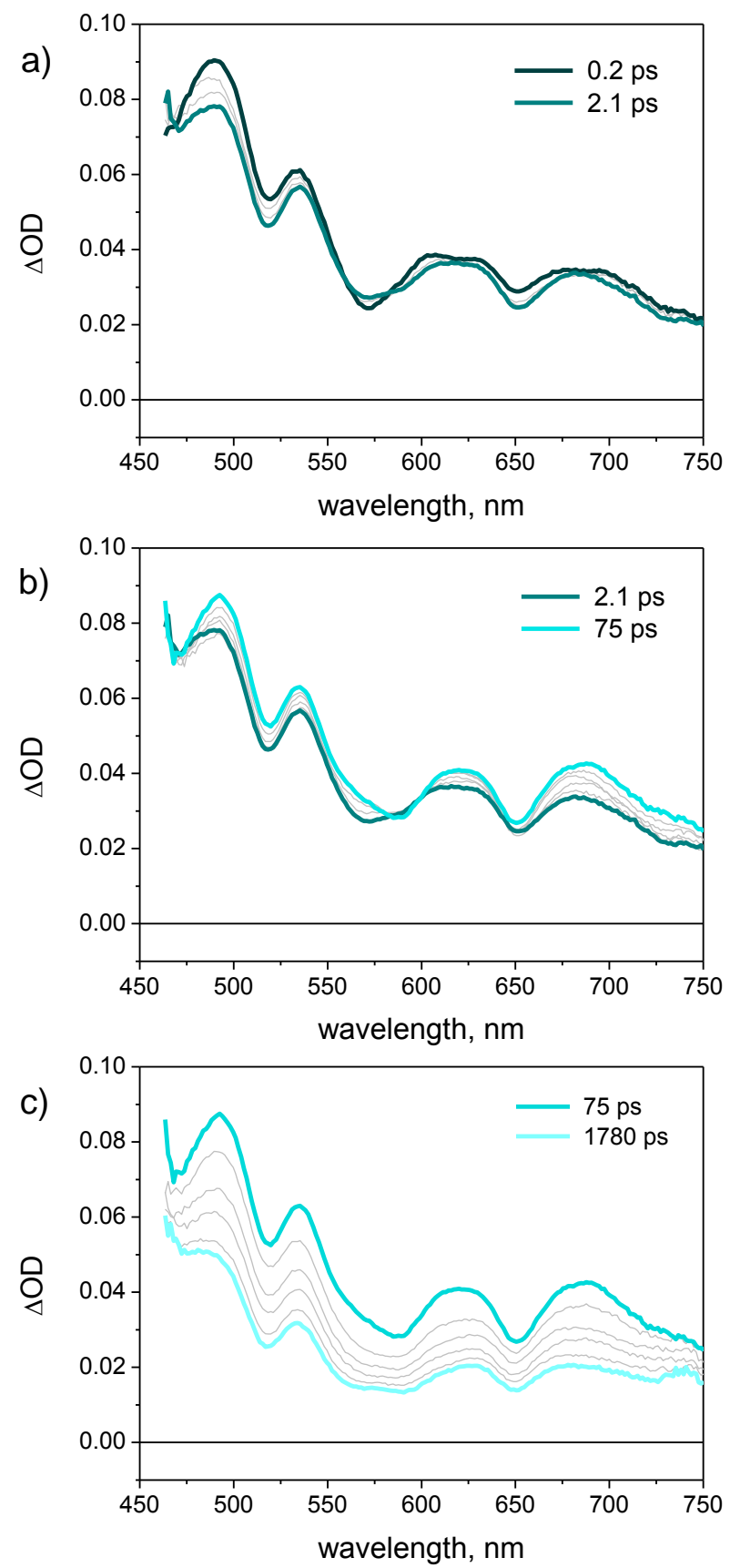

Figure S37. Transient absorption spectra obtained by ultrafast spectroscopy (excitation at $400 \mathrm{~nm}$ ) on a 50/50 ethanol/water solution containing $50 \mu \mathrm{M} \mathrm{Zn1}$ and $50 \mu \mathrm{M} \mathrm{H}_{2} 2$ between (a) 0.2-2.1 ps, (b) 2.1-75 ps, and (c) 75-1780 ps time-delays. 

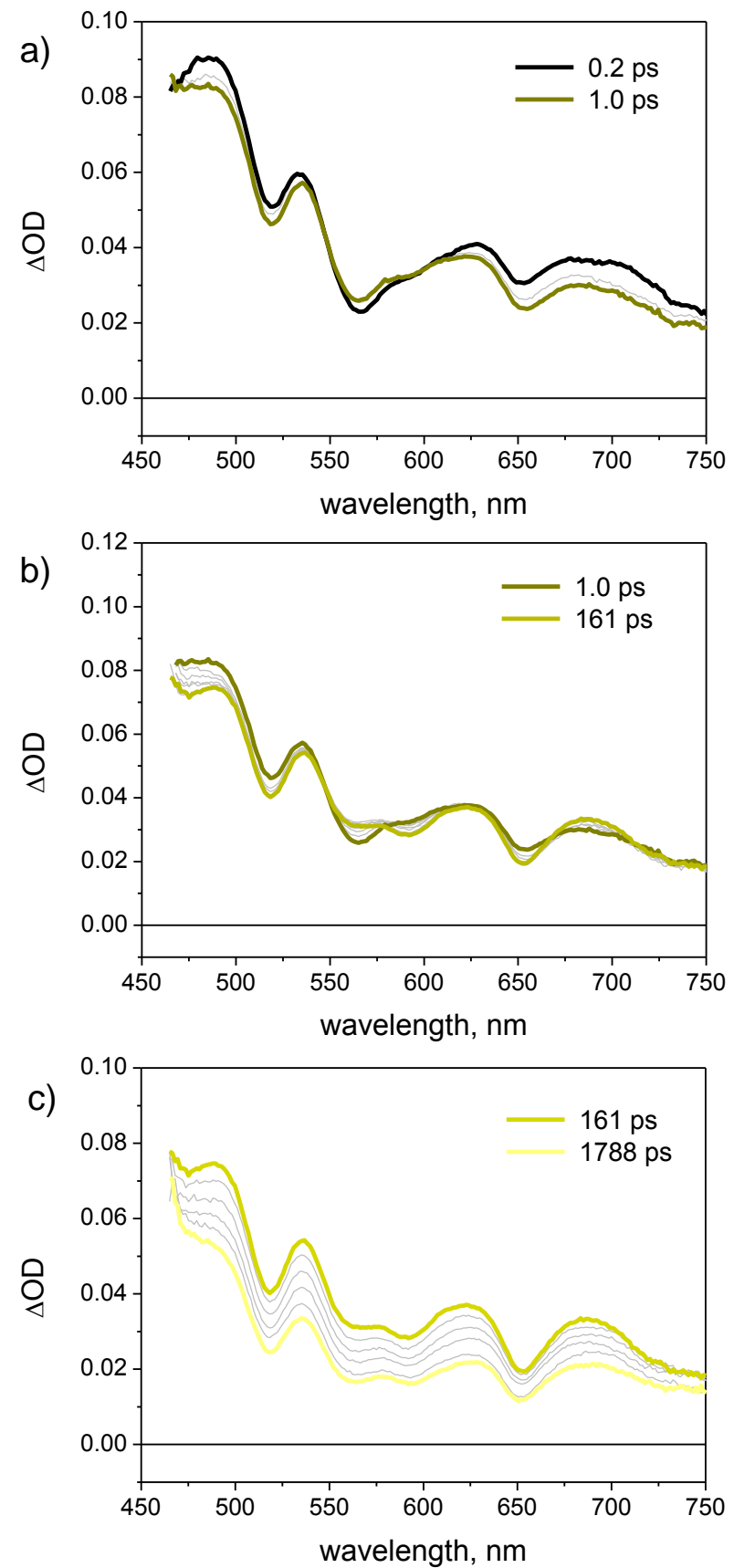

Figure S38. Transient absorption spectra obtained by ultrafast spectroscopy (excitation at $400 \mathrm{~nm}$ ) on a 50/50 THF/water solution containing $50 \mu \mathrm{M} \mathrm{Zn} 1$ and $50 \mu \mathrm{M} \mathrm{H}_{2} 2$ between (a) 0.2-1.0 ps, (b) 1.0-161 ps, and (c) 161-1848 ps time-delays. 

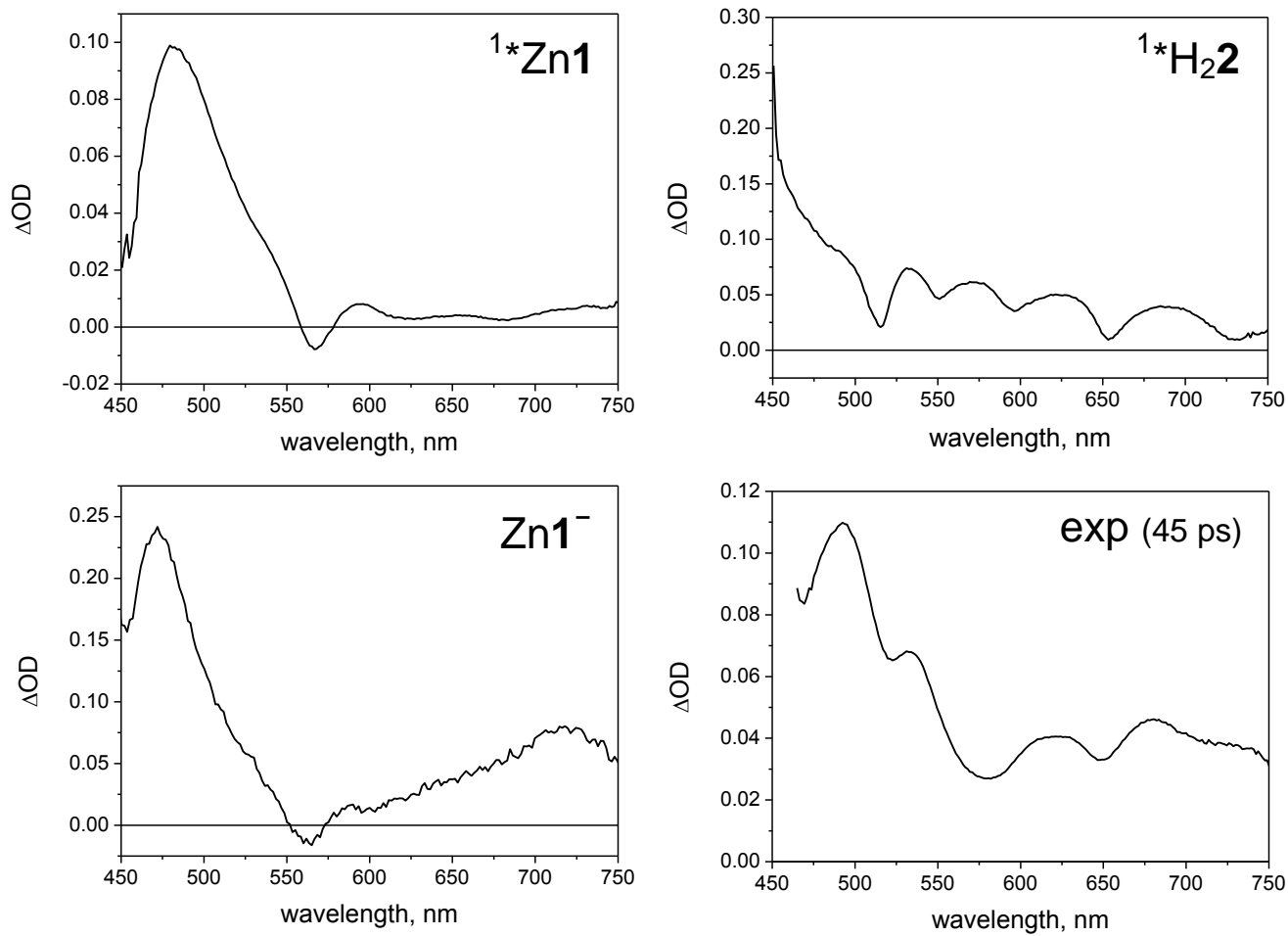

Figure S39. Comparison between the difference absorption spectra of the $\mathrm{Zn} \mathbf{1}$ and $\mathrm{H}_{2} 2$ singlet excited states (obtained by ultrafast spectroscopy of the $\mathrm{Zn} \mathbf{1}$ and $\mathrm{H}_{2} \mathbf{2}$ monomers), $\mathrm{Zn} \mathbf{1}$ radical anion (obtained by flash photolysis of a $\mathrm{Zn} 1$ solution in the presence of $0.01 \mathrm{M}$ ascorbic acid), and the experimental spectrum at 45 ps time-delay from the ultrafast spectroscopy of the $\mathrm{Zn} 1 \mid \mathrm{H}_{2} 2$ ion-pair in 50/50 methanol/water (see Figure 12 of the main text). 

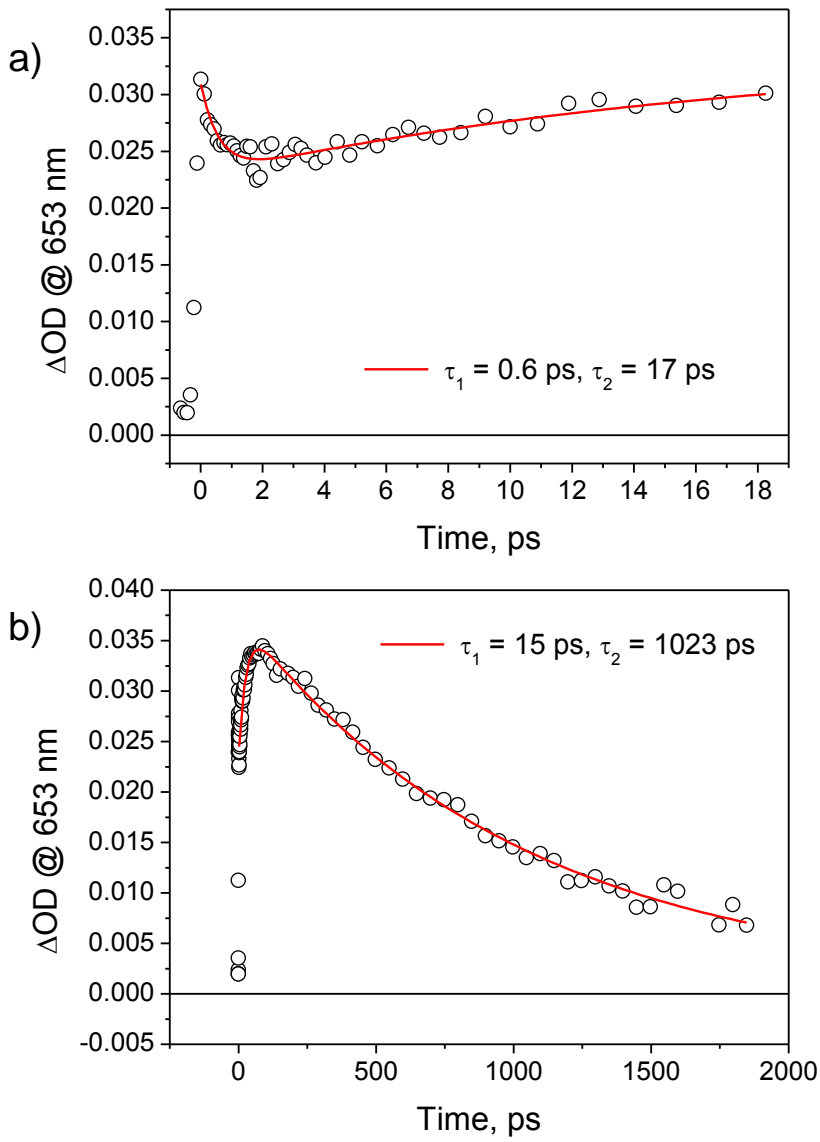

Figure S40. Kinetic traces (and related fitting) at $653 \mathrm{~nm}$ between (a) 0-20 ps and (b) 0-2000 ps obtained by ultrafast spectroscopy (excitation at $400 \mathrm{~nm}$ ) on 50/50 methanol/water solution containing $50 \mu \mathrm{M} \mathrm{Zn1}$ and $50 \mu \mathrm{M} \mathrm{H}_{2} 2$. 

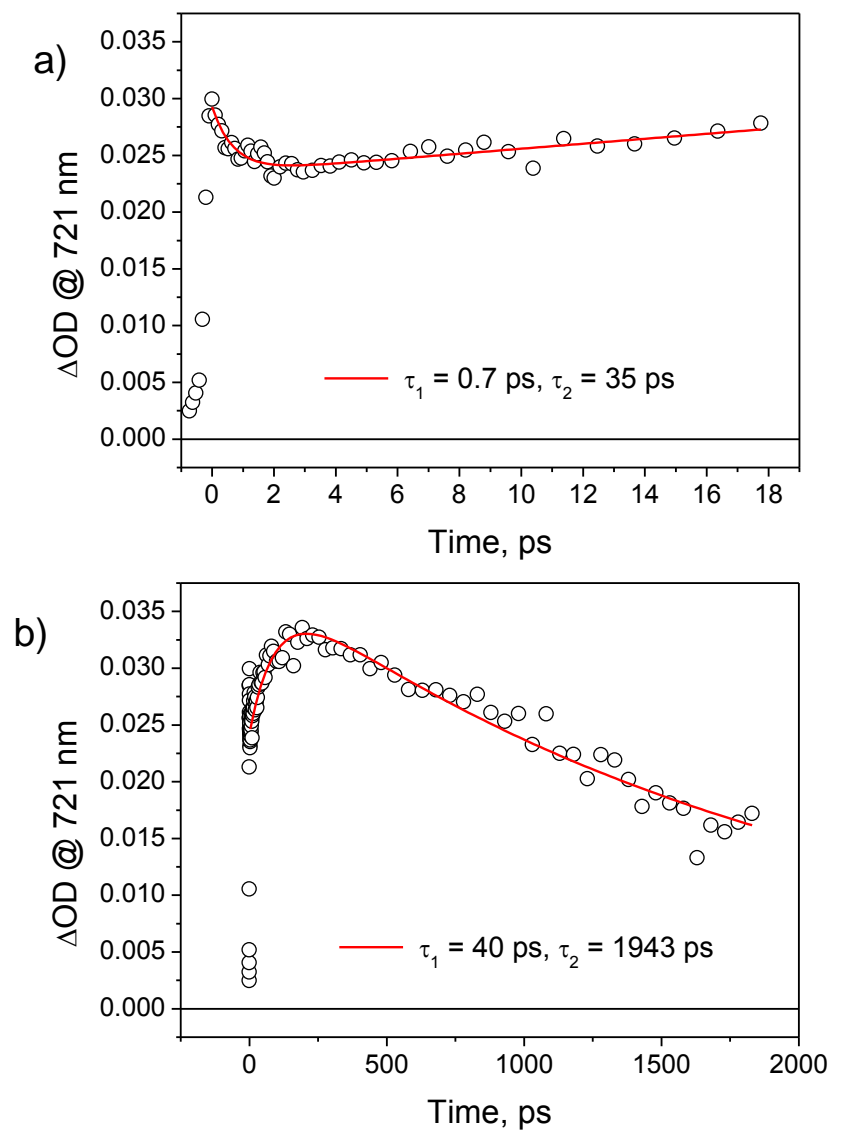

Figure S41. Kinetic traces (and related fitting) at $721 \mathrm{~nm}$ between (a) 0-20 ps and (b) 0-2000 ps obtained by ultrafast spectroscopy (excitation at $400 \mathrm{~nm}$ ) on $50 / 50$ ethanol/water solution containing $50 \mu \mathrm{M} \mathrm{Zn1}$ and $50 \mu \mathrm{M} \mathrm{H}_{2} 2$. 

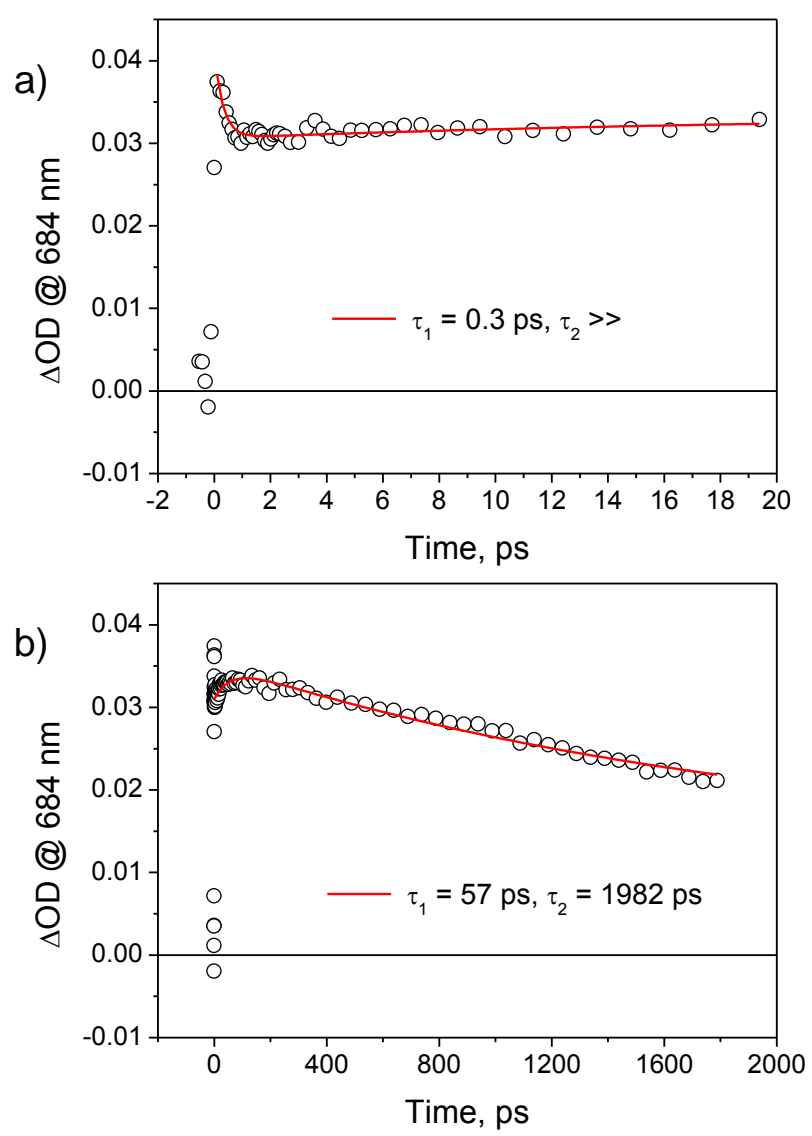

Figure S42. Kinetic traces (and related fitting) at $684 \mathrm{~nm}$ between (a) 0-20 ps and (b) 0-2000 ps obtained by ultrafast spectroscopy (excitation at $400 \mathrm{~nm}$ ) on 50/50 THF/water solution containing $50 \mu \mathrm{M} \mathrm{Zn} \mathbf{1}$ and $50 \mu \mathrm{M} \mathrm{H}_{2} 2$. 

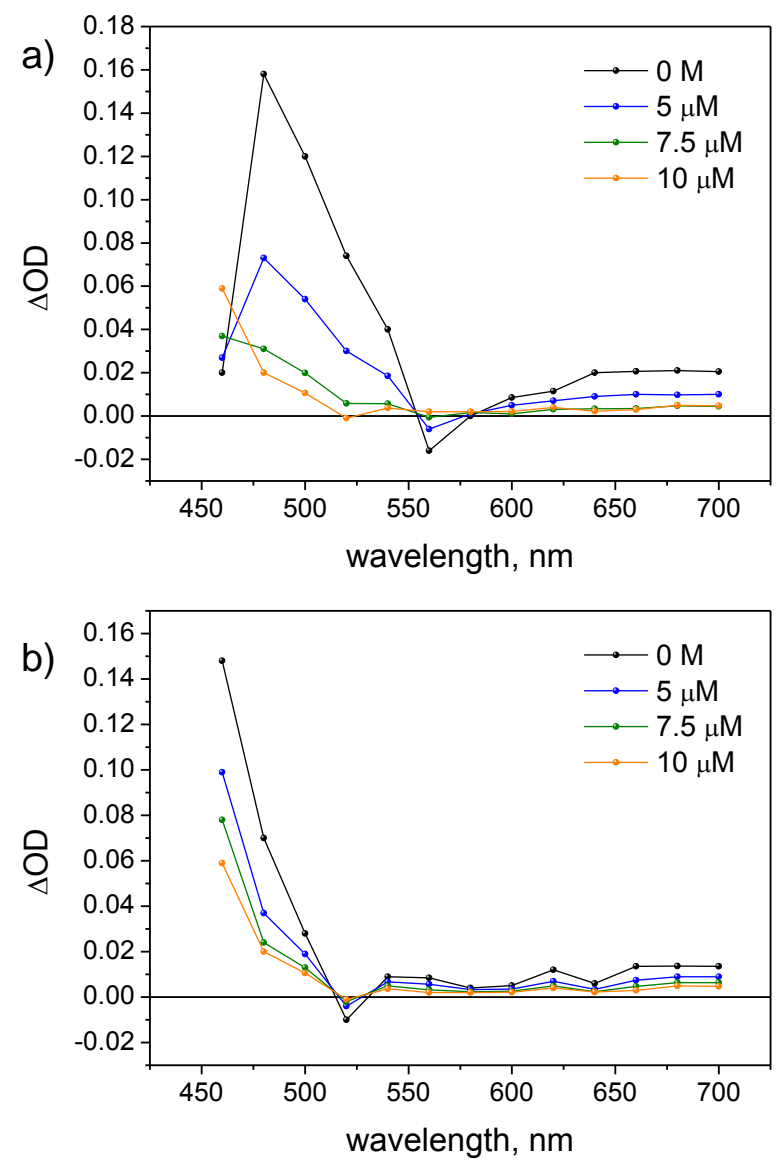

Figure S43. Transient absorption spectra at $15 \mathrm{~ns}$ time delay obtained by laser flash photolysis (excitation at $532 \mathrm{~nm}$ ) in 50/50 methanol/water solutions containing (a) $10 \mu \mathrm{M} \mathrm{Zn1}$ and 0-10 $\mu \mathrm{M}$ $\mathrm{H}_{2} 2$ or (a) $10 \mu \mathrm{M} \mathrm{H} \mathrm{H}_{2} 2$ and $0-10 \mu \mathrm{M} \mathrm{Zn1.} \mathrm{The} \mathrm{spectra} \mathrm{correspond} \mathrm{to} \mathrm{the} \mathrm{transient} \mathrm{spectra} \mathrm{of} \mathrm{the}$ triplet excited state of (a) $\mathrm{Zn} 1$ (except at $10 \mu \mathrm{M} \mathrm{H}_{2} 2$ ) or (b) $\mathrm{H}_{2} 2$ whose decrease in intensity parallels the trend of the emission intensity (Figure S17) upon addition of different amounts of $\mathrm{H}_{2} 2$ or $\mathrm{Zn} 1$, respectively. 

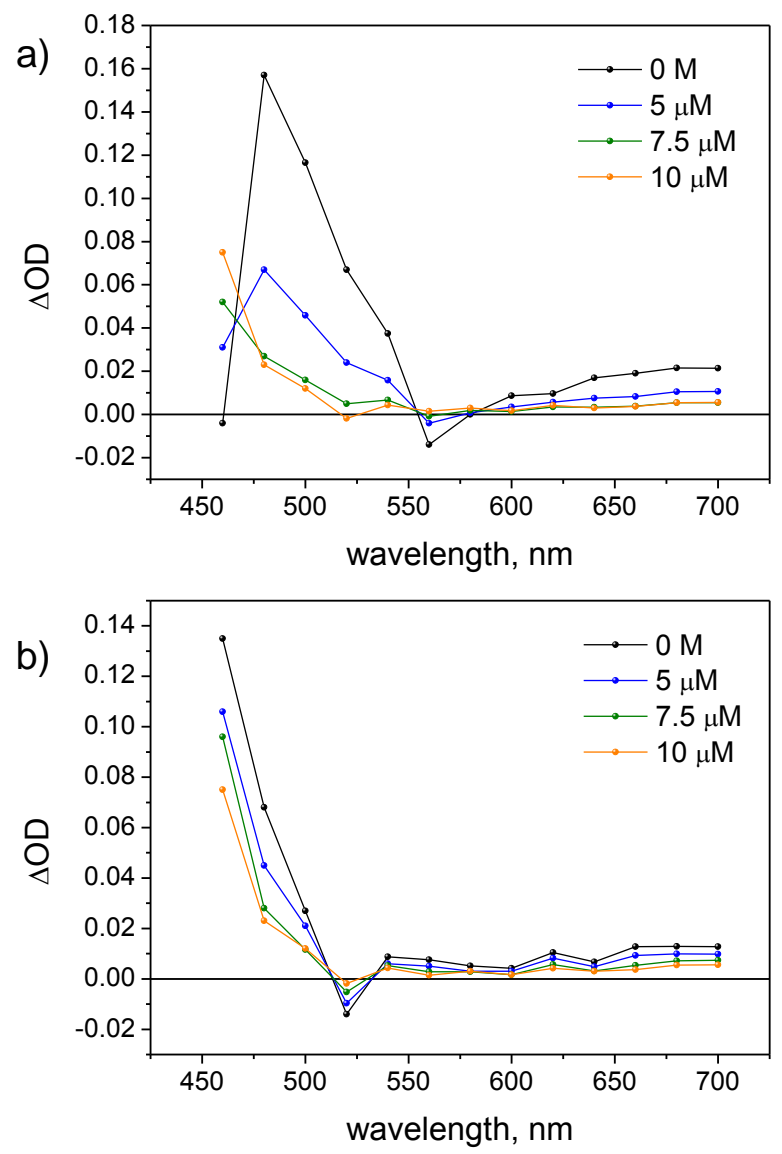

Figure S44. Transient absorption spectra at $15 \mathrm{~ns}$ time delay obtained by laser flash photolysis (excitation at $532 \mathrm{~nm}$ ) in 50/50 ethanol/water solutions containing (a) $10 \mu \mathrm{M} \mathrm{Zn1}$ and 0-10 $\mu \mathrm{M} \mathrm{H}_{2} 2$ or (a) $10 \mu \mathrm{M} \mathrm{H}_{2} 2$ and $0-10 \mu \mathrm{M} \mathrm{Zn} 1$. The spectra correspond to the transient spectra of the triplet excited state of (a) $\mathrm{Zn} 1$ (except at 7.5 and $10 \mu \mathrm{M} \mathrm{H}_{2}$ 2) or (b) $\mathrm{H}_{2} 2$ whose decrease in intensity parallels the trend of the emission intensity (Figure S20) upon addition of different amounts of $\mathrm{H}_{2} 2$ or $\mathrm{Zn} 1$, respectively. 

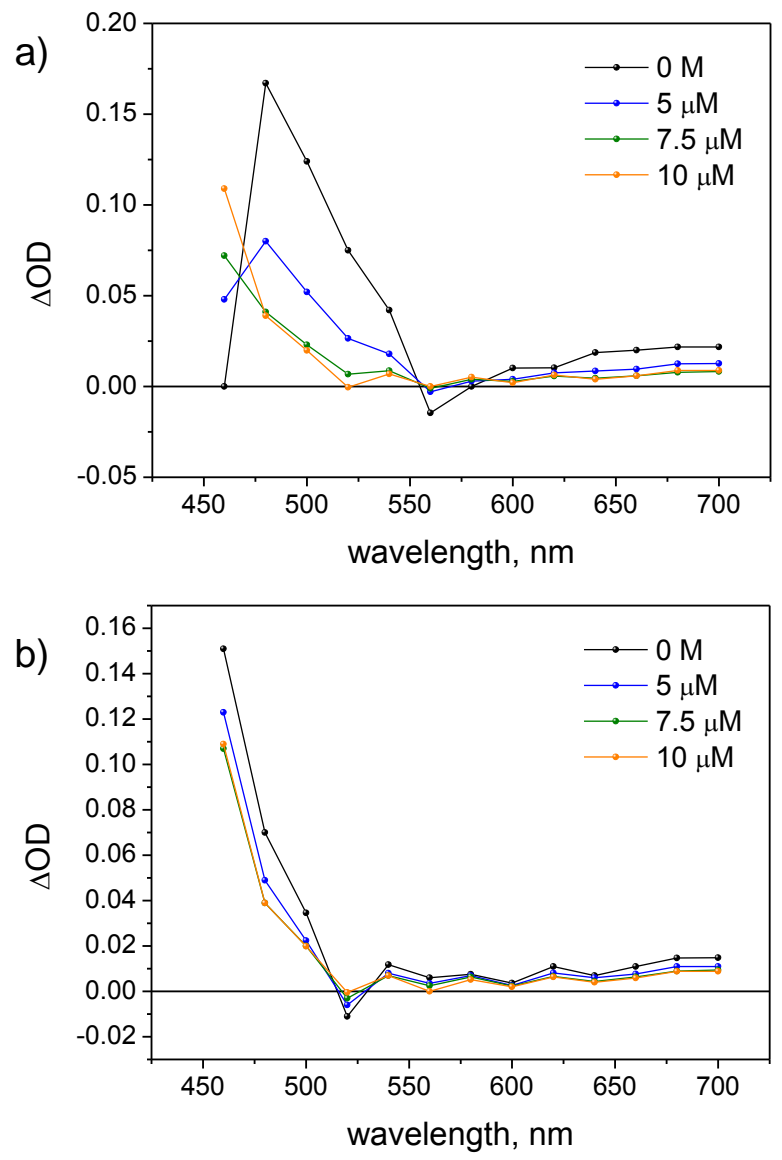

Figure S45. Transient absorption spectra at $15 \mathrm{~ns}$ time delay obtained by laser flash photolysis (excitation at $532 \mathrm{~nm}$ ) in 50/50 THF/water solutions containing (a) $10 \mu \mathrm{M} \mathrm{Zn1}$ and 0-10 $\mu \mathrm{M} \mathrm{H}_{2} 2$ or (a) $10 \mu \mathrm{M} \mathrm{H}_{2} 2$ and $0-10 \mu \mathrm{M} \mathrm{Zn1}$. The spectra correspond to the transient spectra of the triplet excited state of (b) $\mathrm{H}_{2} 2$ whose decrease in intensity parallels the trend of the emission intensity (Figure S21) upon addition of different amounts of $\mathrm{Zn1}$, respectively. (a) Only in the absence of $\mathrm{H}_{2} 2$ the spectrum corresponds to the triplet excited state of $\mathrm{Zn} 1$, important contribution from the triplet excited state of $\mathrm{H}_{2} 2$ starts growing up immediately after its addition in agreement with the emission data. 